\title{
The function and regulation of OTU deubiquitinases
}

\author{
Jiansen $\mathrm{Du}^{1}$, Lin $\mathrm{Fu}^{1}$, Yingli Sui ${ }^{1}$, Lingqiang Zhang $(\varangle)^{2,3}$ \\ ${ }^{1}$ Institute of Chronic Disease, Qingdao Municipal Hospital, Qingdao University, Qingdao 266000, China; ${ }^{2}$ State Key Laboratory of \\ Proteomics, National Center for Protein Sciences (Beijing), Beijing Institute of Lifeomics, Beijing 100850, China; ${ }^{3}$ Peixian People's Hospital, \\ Xuzhou 221600, China \\ (C) The Author(s) 2019. This article is published with open access at link.springer.com and journal.hep.com.cn
}

\begin{abstract}
Post-translational modification of cellular proteins by ubiquitin regulates numerous cellular processes, including cell division, immune responses, and apoptosis. Ubiquitin-mediated control over these processes can be reversed by deubiquitinases (DUBs), which remove ubiquitin from target proteins and depolymerize polyubiquitin chains. Recently, much progress has been made in the DUBs. In humans, the ovarian tumor protease (OTU) subfamily of DUBs includes 16 members, most of which mediate cell signaling cascades. These OTUs show great variation in structure and function, which display a series of mechanistic features. In this review, we provide a comprehensive analysis of current progress in character, structure and function of OTUs, such as the substrate specificity and catalytic activity regulation. Then we discuss the relationship between some diseases and OTUs. Finally, we summarize the structure of viral OTUs and their function in immune escape and viral survival. Despite the challenges, OTUs might provide new therapeutic targets, due to their involvement in key regulatory processes.
\end{abstract}

Keywords ubiquitin; OTU deubiquitinases; structure; function; regulation

\section{Introduction}

Protein ubiquitination is a reversible post-translational modification with key functions in regulating many cellular processes [1]. Ubiquitin is conjugated primarily to lysine and sometimes methionine of target proteins in a cascade of reactions catalyzed by the ubiquitin-activating enzyme (E1), the ubiquitin-conjugating enzyme (E2), and the ubiquitin-ligating enzyme (E3). This process can be reversed by deubiquitinases (DUBs) that cleave ubiquitin off the substrate protein. The equilibrium between ubiquitin conjugation and removal is important and tightly regulated. Its disruption is related to a number of human diseases including inflammatory, neurodegenerative, and metabolic disorders, as well as cancer [2].

The human genome encodes roughly 100 DUBs that fall into seven structural classes: ubiquitin-specific proteases (USPs), ovarian tumor proteases (OTUs), Machado-Joseph domain-containing proteases (MJDs), ubiquitin C-terminal hydrolases (UCHs), MINDYs (motif-interacting with ubiquitin containing proteases), ZUP1 (zinc finger containing ubiquitin peptidase 1) and JAMM/MPN domain-

Received August 3, 2019; accepted October 31, 2019

Correspondence: Lingqiang Zhang, zhanglq@nic.bmi.ac.cn associated Zn-dependent metalloproteases (JAMMs). The subfamily of OTUs has emerged as regulators of important signaling cascades, such as NF- $\kappa \mathrm{B}$ signaling, interferon signaling, DNA damage repair, and immunity $[3,4]$. For example, OTUB1 regulates the DNA damage response [5]; OTUD3 regulates PI3K/Akt signaling [6]; OTUD5 regulates IRF3 signaling [7]; A20 regulates $\mathrm{NF}-\kappa \mathrm{B}$ signaling [8]; OTUD7B controls non-canonical NF- $\kappa \mathrm{B}$ activation in immune regulation [9]; and OTULIN regulates linear ubiquitylation and innate immune signaling as well as angiogenesis [10]. Understanding how OTUs are regulated is important to elucidating the regulatory networks that control ubiquitin signaling. Structural information will be helpful for understanding the mechanisms in which OTUs are involved. This will provide a basis for design of OTU-targeted chemotherapeutic agents. In the first part of the following review we introduce the structure, function and regulation of OTUs; and in the second part we present the roles of OTUs in some human diseases and physiologic processes.

\section{Ubiquitin and ubiquitination}

Ubiquitin (Ub) is a small, conserved globular protein (76 amino acids) with a $\beta$-grasp superfold conformation 
$[11,12]$, consisting of a central $\alpha$-helix surrounded by mixed $\beta$-sheets, and harboring a $\mathrm{C}$-terminal diglycine motif [1] (Fig. 1A). Ubiquitin is often recognized through two hydrophobic surfaces. One consists of Ile44, Leu8, Val7, and His68 (Ile44 patches), the other consists of Ile36, Leu71, and Leu73 (Ile36 patches). The Ile44 patch and Ile36 patch mediate the ubiquitin chain's interaction, and they are recognized by E3s [13], DUBs [14], and some UBDs (ubiquitin binding domains) [15].

A key feature of ubiquitin is its seven lysine residues and its first methionine residue, all of which can be ubiquitinated, thereby allowing the formation of polymeric ubiquitin chains [16]. The Ub-substrate linkages show great diversity (Fig. 1B), and all possible topology linkages have been found in cells $[17,18]$. These include monoubiquitin; multimonoubiquitin; homoubiquitin; mixed and branched-ubiquitin, and unanchored-ubiquitin. Further expanding the signaling complex and variety of ubiquitylation, ubiquitin itself has recently been found to be subjected to post-translational modifications (PTMs), including phosphorylation [19], acetylation [20] and deamidation [21]. Ubiquitin modification provides a series of distinct signals that are used in different functional contexts, with specific signaling needing sophisticated mechanisms for regulation and control. DUBs play an important role in regulating the many layers of the ubiquitin code $[4,22]$.
A

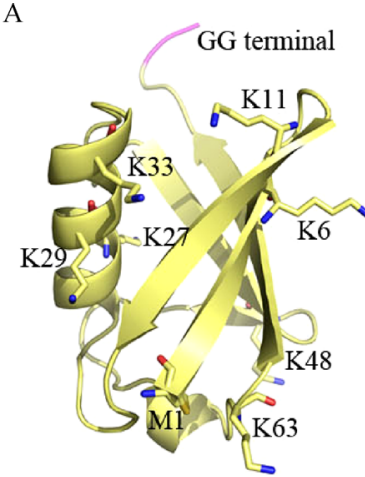

C

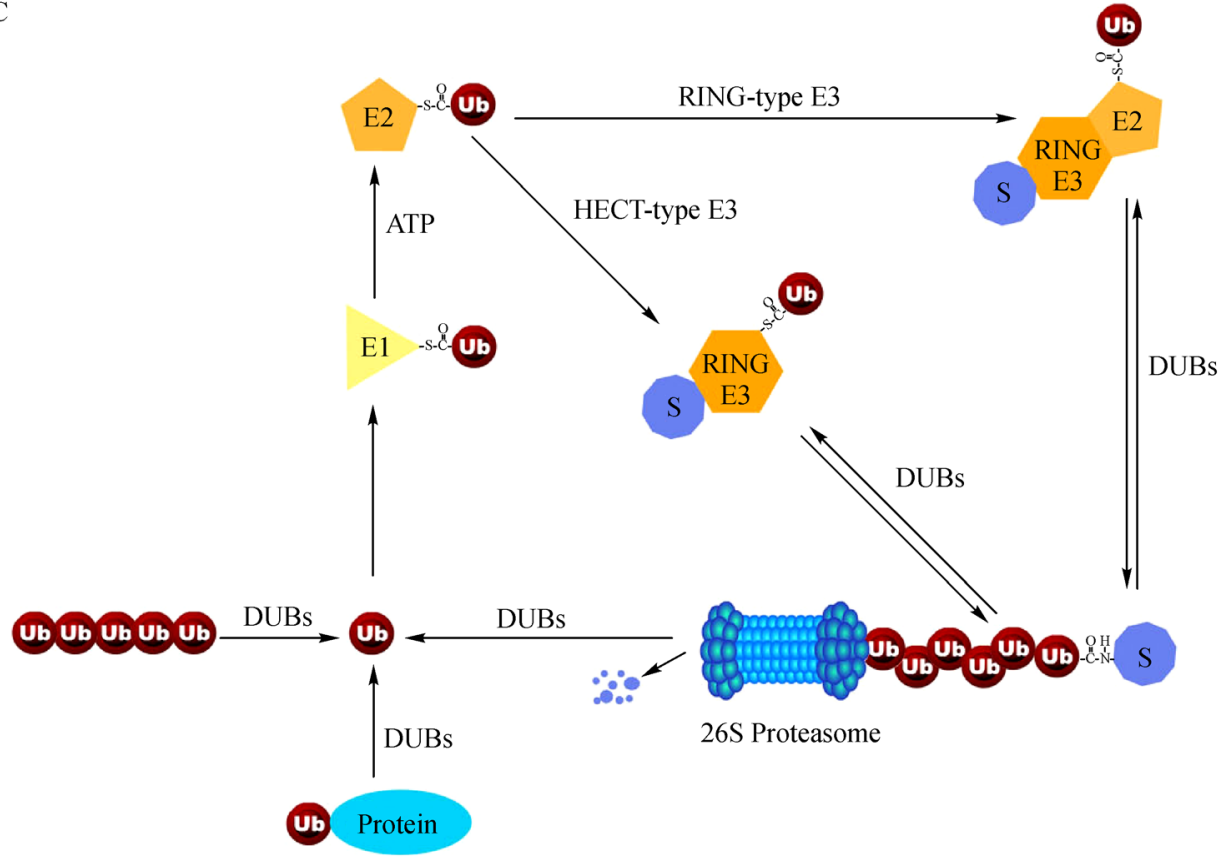

B
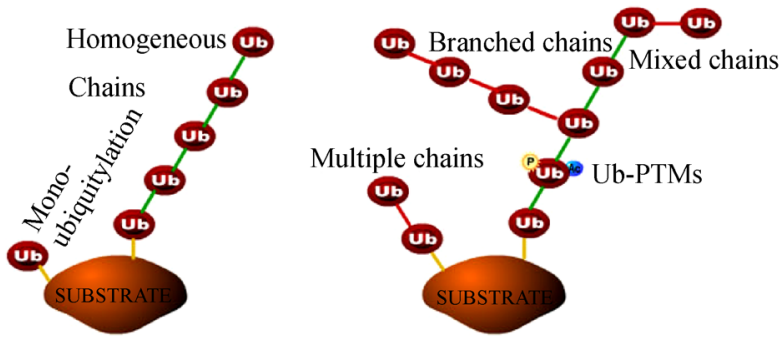

DUBs

Fig. 1 Ubiquitin and UPS pathway. (A) The structure of ubiquitin (PDB: 1UBQ). The seven lysine, N-terminal methionine, and C-terminal diglycine are labeled. (B) The complexity of ubiquitin modifications. Monoubiquitin including seven lysines and one N-terminal methionine gives eight homotypic polyubiquitin chains. Heterotypic types contain mixed or branched linkage type. Also, the cross talk with other PTMs, such as SUMOylation, Neddylation, acetylation (Ac) and phosphorylation (P) enhances the complexity of ubiquitination. (C) A schematic model of UPS (Ubproteasome system) pathway. Ubiquitin modification is an ATP-dependent process carried out by three classes of enzymes: E1, E2, and E3. The reversible process of ubiquitination is countered by DUBs action. 
The process of ubiquitination is reversible and subject to dynamic PTMs that are involved in regulating multiple cellular pathways, including protein degradation, intracellular signaling, cell signaling, transcription, translation, and DNA damage repair [14]. Ubiquitin is covalently conjugated by its terminal glycine onto a lysine residue of its substrate protein using an isopeptide bond. Ubiquitin conjugation to the substrate occurs through an enzymatic cascade involving E1 [23], E2 [24], and E3 [25]. Fig. 1C shows the ubiquitin-proteasome pathway. E1 carries out the ATP-dependent activation of the $\mathrm{C}$ terminus of ubiquitin, forming a covalently bound intermediate with ubiquitin in which the terminal glycine of ubiquitin is linked to the thiol group of a cysteine residue in the E1 active site. Ubiquitin is then transferred to the active site cysteine residue of E2. Finally, E3 catalyzes the transfer of ubiquitin to a lysine residue in the protein substrate (or in some cases the $\mathrm{N}$-terminal $\alpha$-amino group), forming an amide bond.

\section{DUBs}

The removal and rewriting of ubiquitin signals are performed by DUBs, which deal with the vast complexity of the ubiquitin system [26-28]. Mechanisms of action of DUBs include: (1) maintaining protein homeostasis and signaling in cells, (2) maintaining ubiquitin levels, and (3) processing of ubiquitin chains [28,29]. DUBs can reverse the effect of E3 ligases by removing ubiquitin from target proteins, and are also involved in ubiquitin maturation, recycling and editing. Based on the mechanisms of enzymatic cleavage and their structural properties, the approximately 100 human DUBs can be divided into seven subfamilies: USPs, OTUs, UCHs, MJDs, MINDYs, ZUP1, and JAMMs (Fig. 2A) [26,27,30]. USPs, OTUs, MJDs, UCHs, MINDYs, and ZUP1 subfamilies are all cysteine peptidases, whereas JAMMs differ from others by utilizing a zinc metalloproteinase domain to break the ubiquitin-substrate bond.

DUBs hydrolyze the isopeptide bond between ubiquitin and the target protein. Their activity and specificity depend on the ability to recognize ubiquitin. All DUBs have at least one ubiquitin binding site, the $\mathrm{S} 1$ site, which guides the ubiquitin $\mathrm{C}$ terminus and the scissile bond into the active site [22]. The $\mathrm{S} 1$ site selects the modifier, and structural characterizations have shown that the interface between the S1 site and ubiquitin is typically extensive, covering about $20 \%-40 \%$ of the bound ubiquitin molecule [27]. Some biochemical analyses show that the S1 site contributes to the formation of the enzyme-substrate complex. After binding to the $\mathrm{S} 1$ site, the flexible $\mathrm{C}$ terminus of ubiquitin is maximally extended and covered by the DUBs. Linkage type, length, and architecture of ubiquitin chain all impact the DUBs activity [31-33]. In the case of cleaving diubiquitin, the distal ubiquitin occupies the $\mathrm{S} 1$ site, whereas the proximal moiety occupies the $\mathrm{S1}^{\prime}$ site. The substrate or ubiquitin providing the modified lysine residue can be bound by the catalytic domain. In addition, some DUBs feature additional ubiquitin binding sites, such as S2 and S3 (Fig. 2B). These sites enable interaction between the enzyme and long ubiquitin polymers and may contribute to linkage specificity.

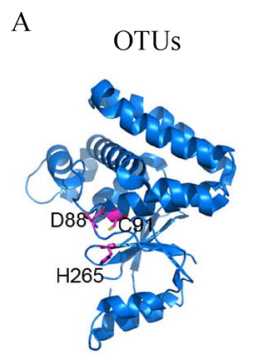

MINDYs

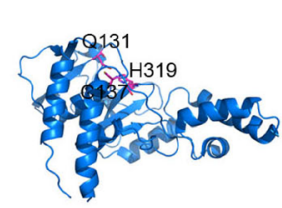



ZUP1
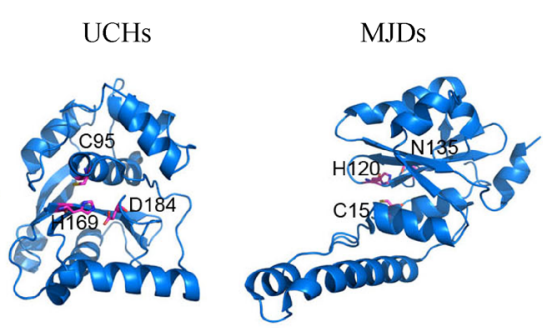

B
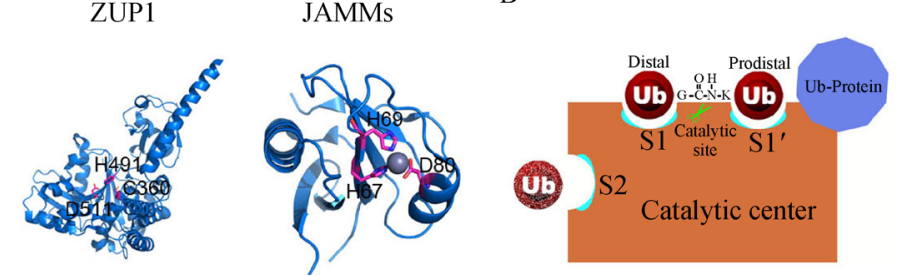

Fig. 2 Structures of the catalytic domain of DUBs. (A) Structure of seven classes of DUBs. The active site cysteine or zinc is shown in magentas. OTUs (OTUB1, PDB: 2ZFG), USPs (USP7, PDB: 1NB8), UCHs (UCH-L3, PDB: 1UCH), MJDs (Ataxin-3, PDB: 3O65), MINDYs (MINDY1, PDB: 5JKN), ZUP1 (ZUP1, PDB: 6FGE), JAMMs (AfJAMM, PDB: 1R5X). (B) Basic nomenclature of OTU catalytic domain. The distal ubiquitin occupies the $\mathrm{S} 1$ site, and the proximal to the $\mathrm{S} 1^{\prime}$ site. Sometimes, additional Ub binding sites, such as S2, S3, and S2' are needed. 


\section{OTUs structure, function and substrate specificity}

The subfamily of OTU deubiquitinases contains 16 members in humans, and has been implicated in human diseases such as cancer, inflammation, neurodegeneration, and virus infection [34]. The OTU domain was first identified in an ovarian tumor gene from Drosophila melanogaster by bioinformatics analysis [35]. The Otu gene product is associated with cell division and differentiation of the cystoblast cell [36,37]. Subsequent studies demonstrated that some members of the OTU family are deubiquitinating enzymes containing putative catalytic cysteine and histidine residues $[28,38]$. Almost all OTUs contain an OTU catalytic domain and an ubiquitin interaction domain, such as an UIM (ubiquitin interacting motif) domain, UBA (ubiquitin associated) domain, or $\mathrm{ZnF}$ (Zinc finger) domain. The structure of the OTU core domain is composed of $\beta$-strands flanked between $\alpha$-helical domains, which are arranged into an anterior $\alpha$-helical domain, a central $\beta$-sandwich domain and a posterior $\alpha$ helical domain $[28,39]$. The active site of OTUs is formed near the center of the OTU surface at the junction between the helical domain and the $\beta$-strands domain. The catalytic cleft is horizontal along the domain interface. The predicted ubiquitin binding domain is located in the right part. To the left of the active site may lay the potential binding surface of the substrates [40] (Fig. 2A). Although the overall structures of OTUs are different from each other, the arrangement of catalytic residues is similar and conserved.

Most DUBs bind ubiquitin via the S1 site and will cleave all linkage polyubiquitin chains [3]. However, some OTUs display remarkable preference for cleaving polyubiquitin chains of certain linkage types (Table 1) [41]. OTUD2 and OTUD3 show remarkable linkage specific reactivity. The catalytic domain of OTUD2 shows a preference for cleaving K11-linked chains, OTUD3 cleaves K6-linked diubiquitin bound [41]. Other OTUs also show chain specificity against different diubiquitin conjugates. For example, A20 cleaves K11 and K48 chains. OTUB1 prefers K48 linkages [42,43], OTUD7A/OTUD7B prefers K11 linkages, Trabid is K29 and K33 specific [44], and OTULIN is Met1 specific [45]. In some cases, UBDs enhance the specificity activity. For example, the Lys29- and Lys33-linked specificity of Trabid depends on its Ank (ankyrin repeat) UBD domain [44]. Similarly, the Lys63 specificity of OTUD1 relies on its C-terminal UIM domain [3].

OTUs are generally isopeptidases that catalyze a proteolytic reaction between a lysine $\varepsilon$-side chain and a carboxyl group of the ubiquitin $\mathrm{C}$ terminus [22] (Fig. 3). Like other cysteine proteases, OTUs share a common catalytic center, which depends on two or three crucial amino residues (cysteine-histidine-aspartic acid) [46]. Mevissen and Komander have reviewed the catalytic mechanisms of DUBs in detail [22]. Briefly, the catalytic cysteine residue of OTUs enables a nucleophilic attack on isopeptide linkages; a nearby histidine side chain lowers the pKa of the catalytic cysteine residue; and a third residue, usually aspartic acid or asparagine, stabilizes and polarizes the catalytic histidine residue [27]. A distinct feature of this catalytic mechanism is a catalytic acyl intermediate, in which the carboxyl group is covalently bound to the catalytic cysteine after the amino group has been cleaved by hydrogen-donating residues, which form an oxy-anion hole nearby. An important role of the oxyanion hole is to orient the histidine residue by $\mathrm{C}-\mathrm{H}-\mathrm{O}$ hydrogen bonding [47]. In a second step, a water molecule hydrolyses the acyl-cysteine intermediate to complete the catalytic cycle [48]. The enzyme is regenerated by a nucleophilic attack of water molecule to acyl intermediates. Although it is diverse in sequence and structural folds, the catalytic triad of OTUs is more or less conserved. Some catalytic triads maybe misaligned in the apo form, but after ubiquitin binding, the active site reorganizes and a correct conformation forms $[27,46]$.

\section{OTUs family}

Based on protein structures and domains, the OTU-type DUBs can be divided into four subclasses: the otubains subfamily (OTUB1 and OTUB2), the OTUD subfamily (OTUD1, OTUD2, OTUD3, OTUD4, OTUD5, OTUD6A, OTUD6B, ALG13), the A20-like OTUs subfamily (A20, OTUD7A, OTUD7B, Trabid, VCPIP1), and the OTULIN subfamily (Fig. 4A). Most human OTUs contain a catalytic domain and additional domains, such as UIM, UBA and $\mathrm{ZnF}$ domain (Fig. 4B). Although they share a similar catalytic mechanism, the sequence and size of the catalytic domain of the four OTUs subfamilies vary widely. The typical structures of the OTUs catalytic domains, diubiquitin binding state and ubiquitin binding state of each subfamily are shown (Fig. 5). The structure of the OTU core domain is arranged like a sandwich, with an anterior $\alpha$-helical domain, a central $\beta$-sandwich domain and a posterior $\alpha$-helical domain [28,39]. The active site of OTUs is formed near the center of the OTU surface in the top-down orientation, and the catalytic cleft runs horizontally along the domain interface. Although the sequence and overall structure of the OTUs are different from both each other and other members of DUBs family members, such as USPs and UCHs, the arrangement of catalytic cysteine and histidine residues is similar and conserved [82]. In the following paragraphs we describe each of the four classes of OTUs in more details.

\section{OTUB subfamily (OTUB1 and OTUB2)}

The OTU enzyme OTUB1 is one of the most abundant DUBs in cells, displays a remarkable specificity for Lys48- 


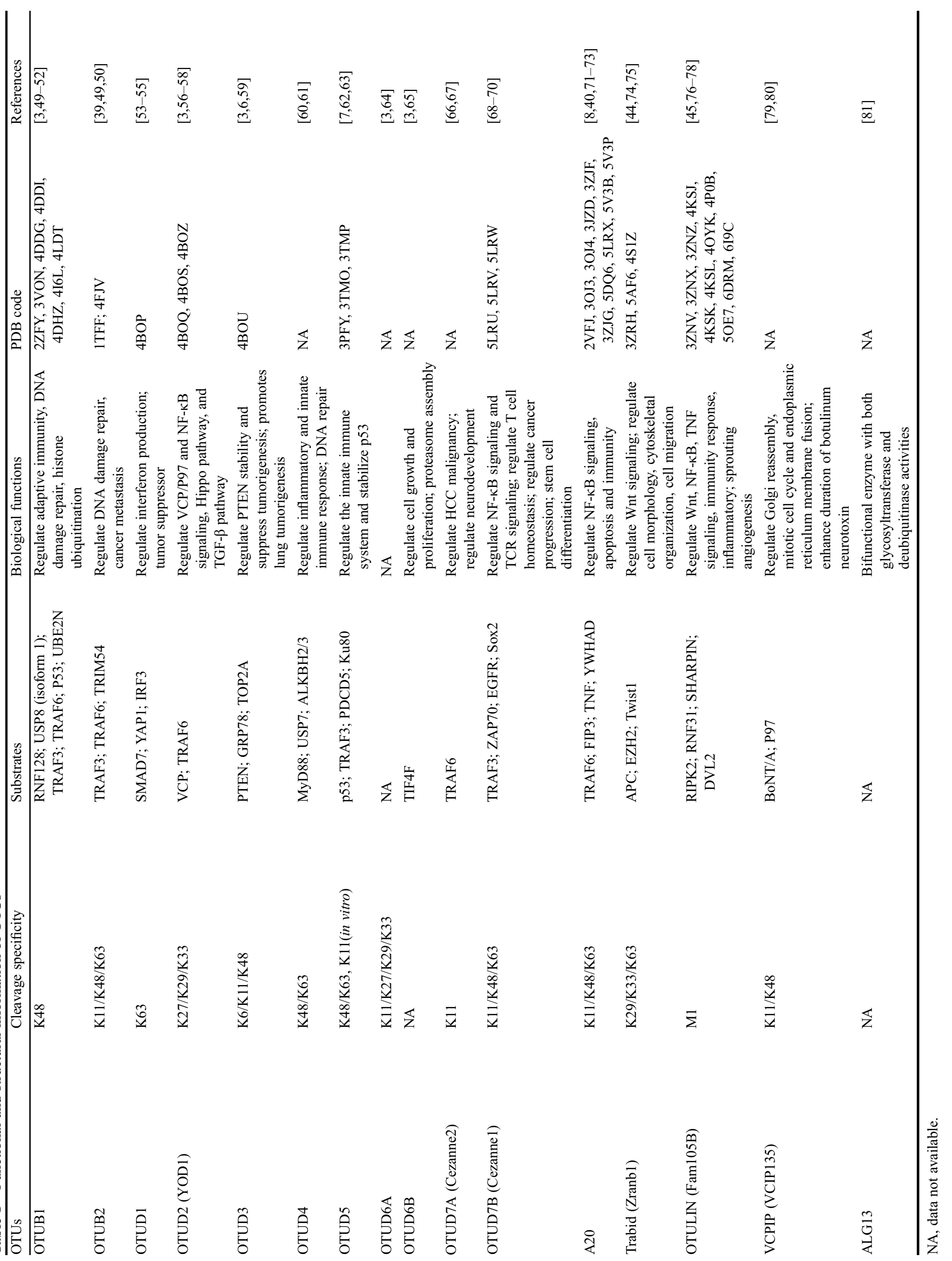




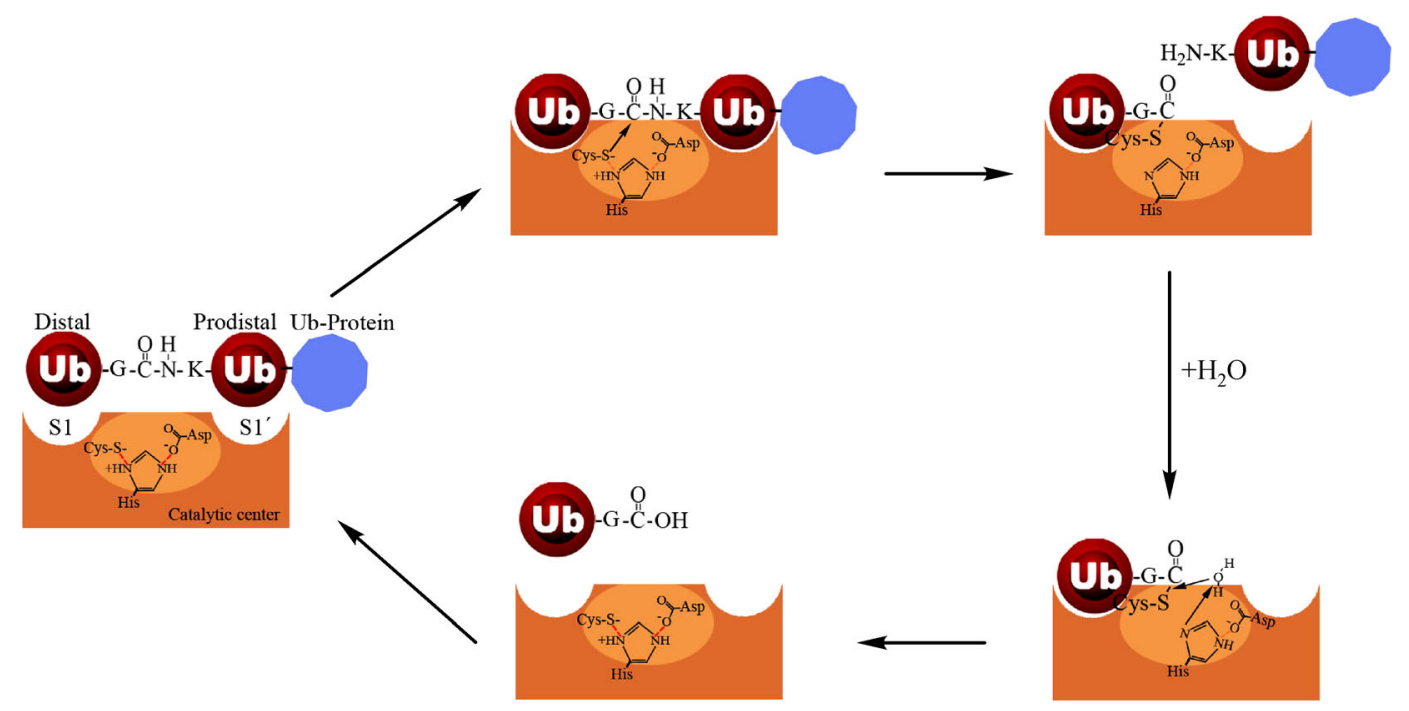

Fig. 3 Catalytic reaction of OTUs. OTUs generally contain a catalytic triad composed of cysteine, histidine and an acidic residue. Upon diubiquitin binding, the deprotonated catalytic cysteine residue attacks the isopeptide linkage, forming a negatively charged tetrahedral intermediate. The proximal Ub releases from the catalytic center, and an acyl intermediate form. A water molecule triggers a deacylation reaction and then the distal Ub releases.
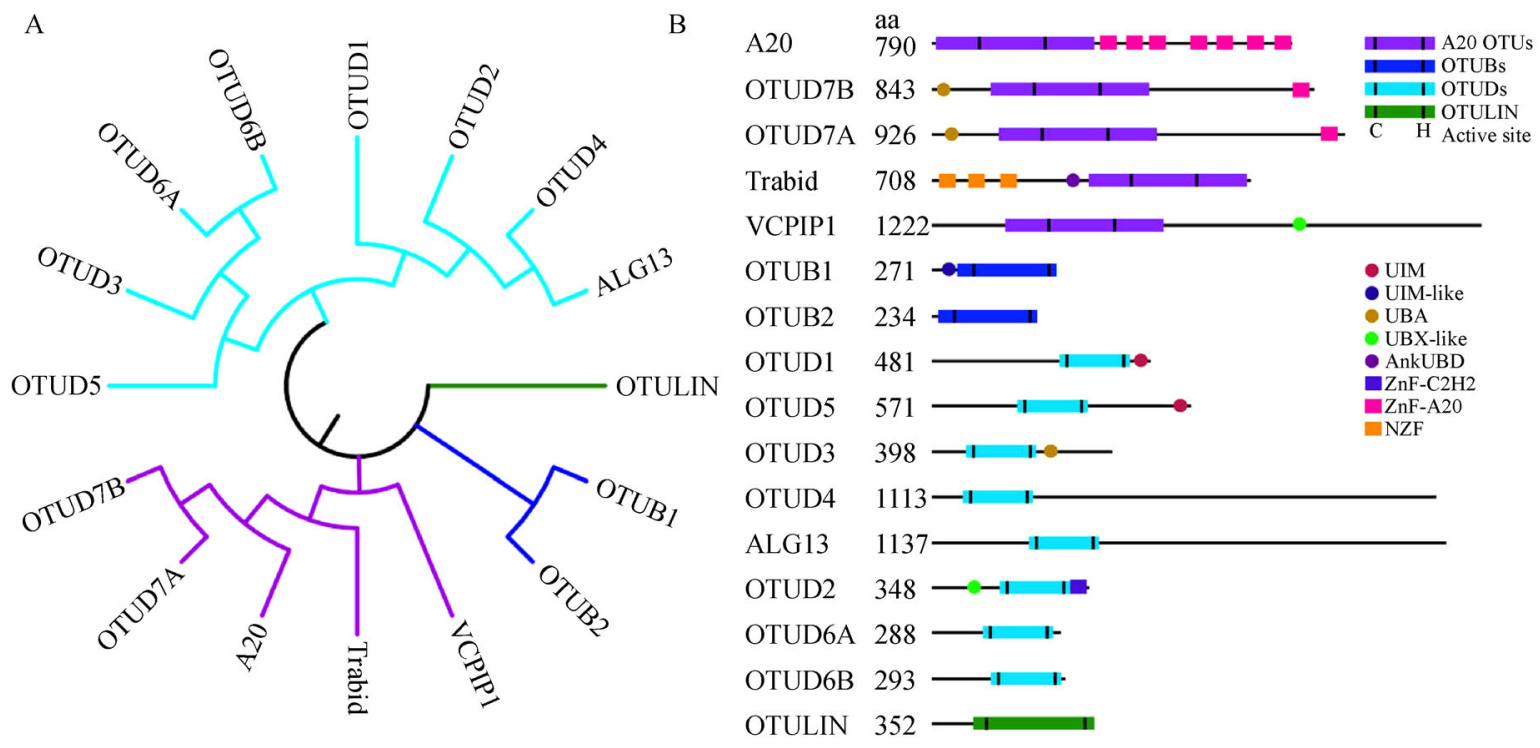

Fig. 4 Phylogenetic tree and domain composition of human OTUs. (A) Phylogenetic tree of human OTUs. (B) Domain composition of human OTUs.

linked chains, and intriguingly, also binds E2 enzymes. OTUB1 contains a structurally disordered N-terminal ubiquitin binding helix that is stabilized upon binding to an E2, such as UBE2N (ubiquitin conjugating enzyme $2 \mathrm{~N}$ ) or UBE2D. This interaction significantly enhances OTUB1 catalytic activity. OTUB1 not only reverses Lys48 ubiquitination but also serves as a powerful inhibitor of various ubiquitination events by regulating E2-ubiquitin conjugates. OTUB1 also possibly acts in part as a buffer or even as a molecular rheostat to sense and regulate equilibrium between cellular free ubiquitin and ubiquitincharged E2 concentrations [5]. OTUB1 participates in mTOR (mechanistic target of rapamycin) complex regulation, which plays an important role in the integration of various environmental signals to regulate cell metabolism, growth, proliferation, and survival. OTUB1 was reported 


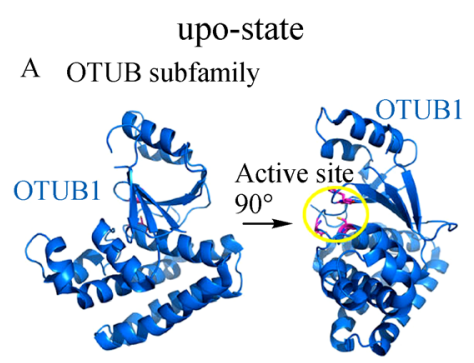

diUb binding state Ub binding state

B OTUD subfamily

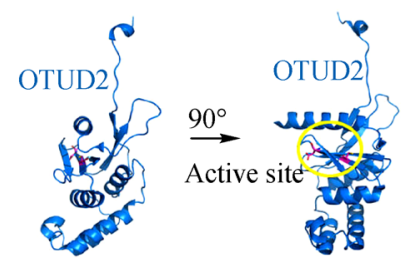

C A20 subfamily

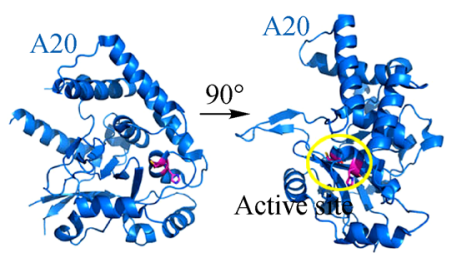

D OTULIN subfamily
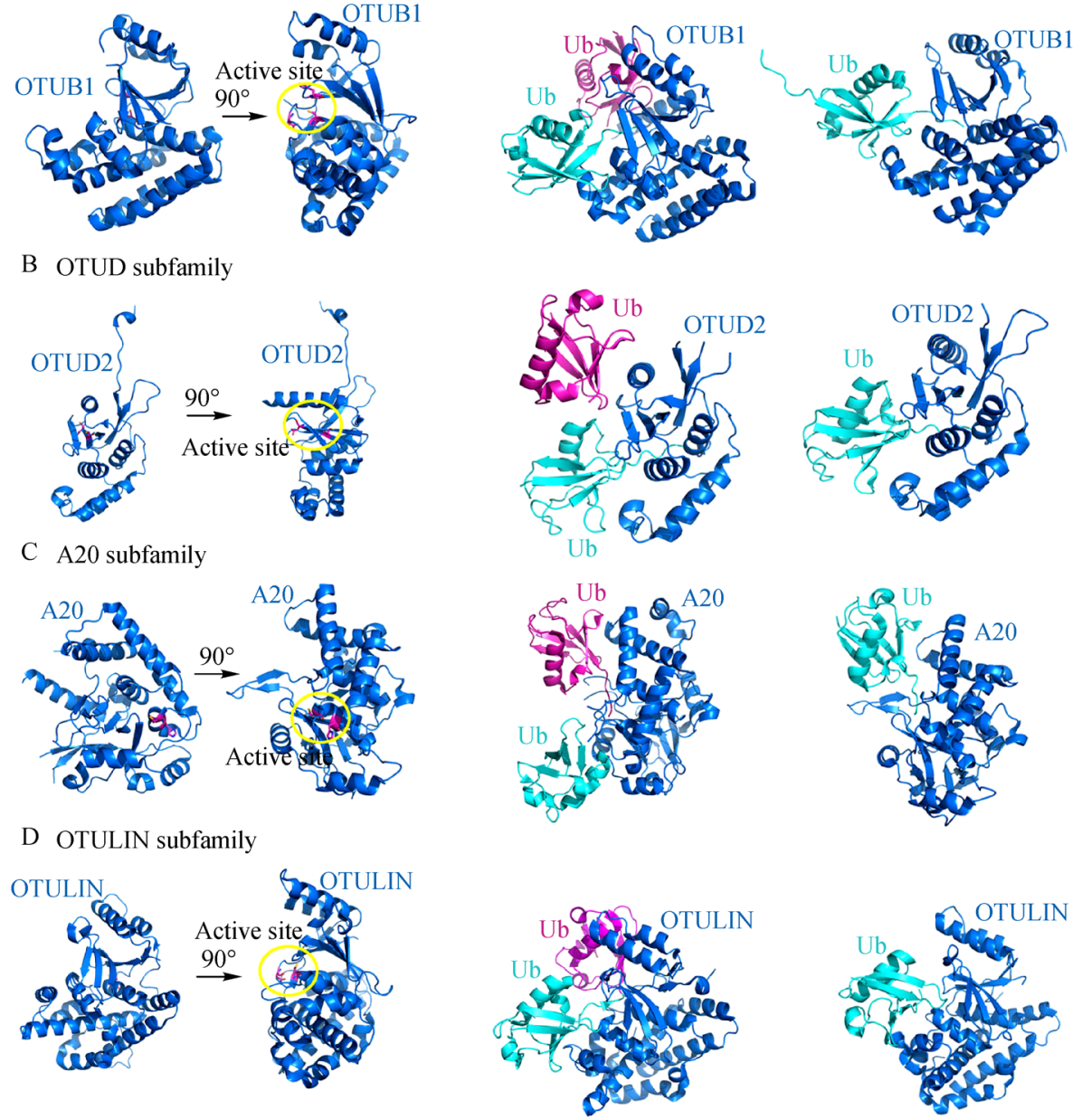

Fig. 5 Structure of OTUs catalytic domain and diubiquitin/ubiquitin binding state. (A) OTUB subfamily (PDB: 2ZFY, 4DHZ, 4FJV); (B) OTUD subfamily (PDB: 4BOQ, 4BOZ, 4BOS); (C) A20 subfamily (PDB: 5LRU, 5LRV, 5LRW); (D) OTULIN subfamily (PDB: 3ZNV, 3ZNZ, 4KSK).

to inhibit mTORC1 activity by deubiquitinating and stabilizing the inhibitor DEPTOR (DEP domain-containing mTOR-interacting protein) in response to amino acid deprivation [83].

A siRNA screen identified that K63-ubiquitin conjugates at DNA DSB (double strands break) sites are further antagonized by OTUB2 [50]. OTUB2 suppresses RNF8 (ring finger protein 8)-mediated L3MBTL1 ubiquitination and K63-linked ubiquitin chain formation in a deubiquitinating activity dependent manner. OTUB2 antagonizes DSB-induced ubiquitination through deubiquitination, while OTUB1 suppresses DSB-induced ubiquitination by inhibiting the E2-conjugating enzymes in a DUB activityindependent manner [5]. Zhang et al. found that OTUB2 enhances breast cancer metastasis by activating the YAP (Yes-associated protein)/TAZ (transcriptional coactivator with PDZ binding motif) pathway through direct deubiquitination and stabilization of both YAP and TAZ. They also show Poly-SUMOylation is required for OTUB2 to interact with and deubiquitinate YAP/TAZ [49]. Since, Zou et al. shows NEDD8 substrate Cul7 acts as a ubiquitin ligase to promote Mst1 degradation, thereby activating YAP signaling and cardiomyocyte proliferation [58]. All these imply OTUB2 may function in cardiac morphogenesis.

\section{OTUD subfamily (OTUD1, OTUD2, OTUD3, OTUD4, OTUD5, OTUD6A, OTUD6B, ALG13)}

\section{OTUD1}

OTUD1 is a 481 amino acid long OTUD subfamily protein containing an UIM domain, which is important in the regulation of K63 chain specificity. OTUD1 is an important DUB that regulates cell growth and apoptosis by directly suppressing p53 ubiquitination in cells that 
keeps its stabilization and activation [84]. Zhang et al. found that loss of OTUD1 enables breast cancer cells to undergo EMT and gain cancer stem cell traits, thereby driving metastatic spread to distant organs. As a potent negative regulator of the TGF- $\beta$ (transforming growth factor- $\beta$ ) signaling pathway, OTUD1 strongly induces EMT (epithelial to mesenchymal transition) and cancer cell stemness [54]. Recently, Zhang et al. revealed novel negative feedback regulation of innate antiviral immune response of OTUD1 [85]. The infection of RNA viruses can upregulate OTUD1 expression, which interacts with and deubiquitinates Smurfl (Smad ubiquitination regulatory factor 1). The accumulation and deubiquitination of Smurf1 facilitates its localization to mitochondria, where Smurf1 interacts with and degrades the MAVS (mitochondrial antiviral-signaling protein)/TRAF (TNF receptor associated factor) 3/TRAF6 signalosome.

\section{OTUD2}

OTUD2, also known as YOD1, can remove conjugated ubiquitin from substrates and participates in endoplasmic reticulum-associated degradation (ERAD) of misfolded lumenal proteins [86]. OTUD2 harbors the essential catalytic DUB activity, but also function as a ubiquitin sensor by its S2 ubiquitin binding site. Ubiquitin binding by OTUD2 stimulates the interaction of OTUD2 with p97, in turn, p97 activates ubiquitin binding of OTUD2. By recruiting PLAA (phospholipase A-2-activating protein), UBXN6 (UBX domain-containing protein 6) and VCP (valosin-containing protein) to damaged lysosome membranes, OTUD2 plays a role in regulation of macroautophagy, including the clearance of damaged lysosome [87].

\section{OTUD3}

As a deubiquitinase of tumor suppressor PTEN (phosphatase and tensin homolog deleted on chromosome ten), OTUD3 specifically interacts with PTEN and inhibits the PI3K (phosphatidylinositol-3-kinases)/AKT (protein-serine-threonine kinase) signaling pathway. OTUD3 transgenic mice exhibit higher levels of the PTEN protein and are less prone to breast cancer tumorigenesis. OTUD3 is an essential regulator of PTEN and the OTUD3-PTEN signaling plays a critical role in tumor suppression [6]. However, Du et al. recently demonstrated that OTUD3 promotes a tumor in lung cancer by maintaining GRP78 (a glucose-regulated protein $78 \mathrm{kDa}$ ) protein levels [59]. To evaluate the physiologic role of OTUD3 in tumorigenesis, knockout mice were generated. The data show that the pathological function of OTUD3 is different in different tissues, such as a suppressor of breast cancer, a promoter of lung cancer. This finding means that the function of some OTUs relies on cell or tissue specificity; an effective cancer treatment strategy should take this specificity in consideration.

\section{OTUD4}

OTUD4 negatively regulates inflammatory signaling; and as a RBP (RNA binding protein), OTUD4 regulates RNA granules. Through the IL-1 receptor and TLR signaling pathways, OTUD4 deubiquitinates K63-linked ubiquitin of MYD88 (myeloid differentiation primary response 88) adapter, and triggers downregulation of NF- $\kappa \mathrm{B}$ dependent transcription of inflammatory mediators [61]. OTUD4 deubiquitinates and stabilizes ALKBH3 ( $\alpha$-ketoglutaratedependent dioxygenase alkB homolog 3 ), and promotes the repair of alkylated DNA lesions [60]. Das et al. reveal that OTUD4 is a RBP, is present in neuronal RNA granules, and plays a role in translation. Under physiologic conditions, OTUD4 is required for proper formation of cytoplasmic stress granules during acute cellular stress [88]. Their work opens up new lines of research regarding OTUD4 as a RBP, and the function of an OTU in translation regulation and RNA granules. Future work will be needed to investigate the details and mechanisms of these processes.

\section{OTUD5}

OTUD5 deubiquitinates TRAF3 and subsequently inhibits IFN production, functioning as a negative regulator of innate immunity [89]. Phosphorylation of OTUD5 at a single residue, Ser177, is both necessary and sufficient to activate the enzyme [7]. de Vivo et al. described a new role of OTUD5 in chromatin damage response wherein the OTUD5-UBR5 (E3 ubiquitin-protein ligase UBR5) complex regulates FACT (facilitates chromatin transcription)mediated transcription as a response to DNA damage [90]. Further investigation into the nature of the interaction between OTUD5 and FACT will provide more insight into this regulation.

\section{OTUD6A and OTUD6B}

OTUD6A and OTUD6B show great similarity $(56 \%$ identity), but the publication of OTUD6A is much less than OTUD6B. OTUD6B primary transcripts can be alternatively spliced to yield three splice variants. Variant 1 contains an N-coiled coil domain, variant 2 lacks the Ncoiled coil domain, and variant 3 has a short N-terminal deletion [65]. The function of OTUD6B associates with protein synthesis initiation complex and modifies the preinitiation complex. OTUD6B operates downstream from mTORC1 and regulates protein synthesis in NSCLC (non-small cell lung cancer) cells. The two main OTUD6B splicing isoforms (isoform 1 and isoform 2) 
seem to regulate protein synthesis in opposing fashions: the long OTUD6B-1 isoform acts as a repressor of general protein synthesis, but the short OTUD6B-2 isoform seems to stimulate protein synthesis [65]. OTUD6B can repress DNA synthesis and modify different cellular targets, thereby regulating cell growth and proliferation [65]. OTUD6B may also play a role in proteasome assembly and function [91]. OTUD6B-AS1 (OTUD6B antisense RNA1) might also be a novel negative regulator of apoptosis in systemic sclerosis [92]. Wang et al. recently presented a novel mechanism by which lncRNA OTUD6B-AS1 can inhibit ccRcc (clear cell renal cell carcinoma) proliferation via the $\mathrm{Wnt} / \beta$-catenin signaling pathway [93].

\section{ALG13}

ALG13 (asparagine-linked glycosylation 13 homolog) is a putative bifunctional enzyme, with UDP-N-acetylglucosamine transferase and deubiquitinase activities. Gao et al. found that ALG13 expression in the central nervous system (CNS) had histological and cellular specificity, mainly in the epilepsy related regions, such as cortex and hippocampus. They also gave the possible mechanisms of ALG13 in epilepsy by hyperactive mTOR signaling pathway in the cortex and hippocampus. This is the first evidence of the association between ALG13 and epilepsy in experimental animals [81]. But until now, the research on the deubiquitinase activity of ALG13 is still rare.

\section{A20-like subfamily (A20, OTUD7A, OTUD7B, Trabid, VCPIP)}

A20

Human A20 localizes to chromosome 6 and encodes a 790 amino acid protein which contains an $\mathrm{N}$-terminal protease domain and a C-terminal zinc finger domain. A20 possesses two seemingly opposing ubiquitin editing activities, having both E3 ubiquitin ligase and deubiquitinase activity. As a negative regulator of NF- $\mathrm{B}, \mathrm{A} 20$ is involved in both immune and inflammatory regulation. Upon TNF (tumor necrosis factor) stimulation, A20 deubiquitinates K63-linked polyubiquitin chains on RIPK1 and TRAF6, and catalyzes the formation of K48linked polyubiquitin chains. These results of RIPK1 degradation and termination are from TNF-mediated activation of NF- $\kappa B$ [94]. A20 also inhibits NF- $\kappa B$ at the level of the IKK complex by deubiquitination of NEMO $(\mathrm{NF}-\kappa \mathrm{B}$ essential modulator)/IKK $\gamma$ (IкB kinase $\gamma$ ) $[40,95]$. Upon TCR ( $T$ cell receptor)-mediated $T$ cell activation, A20 deubiquitinates MALT1 (mucosal-associated lymphoid tissue 1), thereby mediating disassociation of the CBM (CARMA1-BCL10-MALT1 signalosome) and IKK complexes, and preventing sustained IKK activation [96,97]. The zinc finger domain of A20 targets TRAF2 for lysosomal degradation [98]. Yang et al. found that A20 regulates the DNA damage response and mediates tumor cell resistance to DNA damage therapy [99].

\section{OTUD7A and OTUD7B}

OTUD7A and OTUD7B target Lys11-linked ubiquitin chains with high specificity. The high expression level of OTUD7A in the CNS system indicates its important function in nervous system development. Yin et al. found that OTUD7A is important in regulation of dendritic spine density and activity, and revealed that OTUD7A is crucial for the development and function of the CNS [100]. Otud7a knockout mice have recapitulated cardinal phenotypes associated with $15 \mathrm{q} 13.3$ microdeletion syndrome, such as developmental delay, intellectual disability, epilepsy, language impairment, abnormal behaviors, neuropsychiatric disorders, and hypotonia $[67,100]$.

OTUD7B plays important roles in NF- $\kappa \mathrm{B}, \mathrm{mTOR}$, and hypoxia signaling, as well as in neural stem cell differentiation [9,101]. Wang et al. found that OTUD7B and TRAF2 govern an ubiquitin dependent switch that regulates mTORC2 signaling [102]. The TRAF2 E3 ubiquitin ligase promotes K63-linked ubiquitin of G $\beta \mathrm{L}$. This modification disrupts the interaction between G $\beta L$ (protein GbetaL) and the unique mTORC2 component SIN1, thus favoring mTORC1 formation. In contrast, OTUD7B removes the ubiquitin chains from $G \beta L$ to promote G $\beta$ L interaction with SIN1, facilitating mTORC2 formation in response to various growth signals. Growth factor signaling triggers OTUD7B-mediated G $\beta \mathrm{L}$ deubiquitination to promote mTORC2 integrity, thus favoring tumorigenesis. $\mathrm{Hu}$ et al. found that OTUD7B controls noncanonical NF- $\kappa \mathrm{B}$ activation by deubiquitination of K63-linked TRAF3. As a pivotal negative regulator of the noncanonical NF- $\kappa$ B pathway, OTUD7B has been implicated in TRAF3 deubiquitination. This is different from OTUD5 regulation of K63 ubiquitination and the nondegradative function of TRAF3 in the PPR-induced IFN-1 signaling pathway $[9,89]$. OTUD7B can also, by reducing K63-linked ubiquitin of TRAF6, inhibit NF- $\mathrm{B}$ dependent inflammation activation in response to hypoxia-reoxygenation [103]. Furthermore, Cui et al. revealed that OTUD7B seems to be a specific DUB for Sox 2 and maintains NPCs (neural progenitor cells) property by the removal of ubiquitin from Sox2. OTUD7B is highly expressed in ESCs (embryonic stem cells) and NPCs, suggesting that it might play a wide role in this regulation. However, elucidation of this role requires further deep studies [69].

The crystal structure of OTUD7B illuminated the specificity mechanism of it. In the absence of an 
ubiquitination state, OTUD7B is autoinhibited, but is able to bind a ubiquitin chain due to the open S1 site [68]. Large conformation changes occur in the OTU domain between unbound and diubiquitin-bound states. Lys 11 diubiquitin binding to $\mathrm{S} 1$ site exposes hydrophobic residues and contributes to the $\mathrm{S} 1^{\prime}$ site formation in situ. The mechanism of OTUD7B shows the potential plasticity of OTUs and suggests that the $\mathrm{S} 1$ and $\mathrm{S}^{\prime}$ sites may be dynamic remodeling [68].

\section{Trabid}

Trabid exhibits a remarkable preference for K63-linked ubiquitin with its three tandem NZF fingers, and is required for efficient TCF (transcription factor)-mediated transcription in cells with high Wnt activity. Tran et al. found that Trabid can bind and deubiquitylate the tumor suppressor protein APC (adenomatous polyposis coli protein), a negative regulator of Wnt-mediated transcription [104]. Furthermore, the effect of Trabid on APC appears to function in downstream of $\beta$-catenin stabilization, and APC may decrease the rate of TCF- $\beta$-catenin complex formation, which is seemingly dependent on K63 ubiquitination of APC. Trabid plays a role in the regulation of cell morphology, cytoskeletal organization, and cell migration $[44,105]$. A report by Jin et al. demonstrated that the production of IL-12 and IL-23 is under control of Trabid. This study revealed a new role for Trabid in driving inflammatory $\mathrm{T}$ cell responses and indicates that the mechanism is Trabid-mediated deubiquitination and stabilization of the demethylase Jmjd2d (lysine-specific demethylase 4D), which negatively regulates the repressive histone methylation marks at the IL12 (interleukin-2) and IL23 promoter [106,107].

\section{VCPIP}

VCPIP is necessary for VCP-mediated reassembly of Golgi stacks after mitosis [80]. Another function of VCPIP is in VCP-mediated formation of transitional endoplasmic reticulum (tER). Tsai et al. found that VCPIP stabilizes LCA (light chain A), an extraordinarily stable catalytic light chain of BoNT/A (BoNT serotype), thereby limiting BoNT/A degradation by the proteasome, and this results in the duration of botulinum neurotoxin type A intoxication [79].

\section{OTULIN subfamily (OTULIN)}

OTULIN is the only known Met1-specific DUB. It binds Met1-linked chains with high affinity to the S1 and S1' sites in a manner such that only the N-terminal Met1 residue of the proximal ubiquitin is adjacent to the active site [108]. Importantly, OTULIN uses a mechanism of ubiquitin-assisted catalysis whereby the proximal ubiquitin moiety releases an autoinhibited state of the catalytic center [45]. OTULIN specifically removes Met1-linked linear polyubiquitin chains from substrates and acts as a regulator of both angiogenesis and innate immune response [10,45,109]. OTULIN interacts with HOIP (HOIL-1L interacting protein)/RNF31, a key component of LUBAC (linear ubiquitin chain assembly complex), and counteracts LUBAC activity, further regulating canonical Wnt signaling [108]. The HOIP-OTULIN interaction has evolved to be both specific and high-affinity [110]. By interacting with the LUBAC complex and downregulating TNF $\alpha$, OTULIN inhibits LUBAC-mediated NF- $\kappa \mathrm{B}$ signaling [45]. As a key negative regulator of inflammation, OTULIN restricts spontaneous inflammation and maintains immune homeostasis [10]. Heger et al. showed that OTULIN promotes rather than counteracts LUBAC activity by preventing its auto-ubiquitination with linear polyubiquitin. These results highlight a new interaction between linear ubiquitination, cell death regulation, and type I interferon induction [111].

\section{Regulation mechanism of OTUs}

In vitro, the activity of OTUs is often low, indicating the presence of widespread activation mechanisms imposed by the cellular environment. The variety of mechanisms for OTUs to interact with ubiquitin and substrates correspondingly enables enough regulatory mechanisms to fine-tune OTUs function. The substrate binding site can be occluded, the catalytic triad of some OTUs seems to be in an inactive conformation, and a conformational change is necessary for its activity. All ubiquitin dependent processes, such as post translational modification, oxidation and allosteric interactions, and their abundance and subcellular localization, are tightly regulated [27].

\section{Post-translational modifications (PTMs)}

The extensive crosstalk between ubiquitin signaling networks and other PTMs, such as phosphorylation (Fig. 6A), ubiquitylation, acetylation (Fig. 6B), and SUMOylation, is an important way to adjust the OTUs catalytic activity. Phosphorylation is a key PTM that can modulate DUB activity both positively and negatively. The regulation mechanism of OTUD5 is the most well understood example used to explain phosphorylation regulation. CK2 (casein kinase 2)-mediated Ser177 phosphorylation within the catalytic domain activates OTUD5 activity, representing the first example of how phosphorylation could activate a DUB [7,112]. The phosphorylated loop can stabilize the enzyme and exclude water molecules from the active site. This example reveals the regulatory 

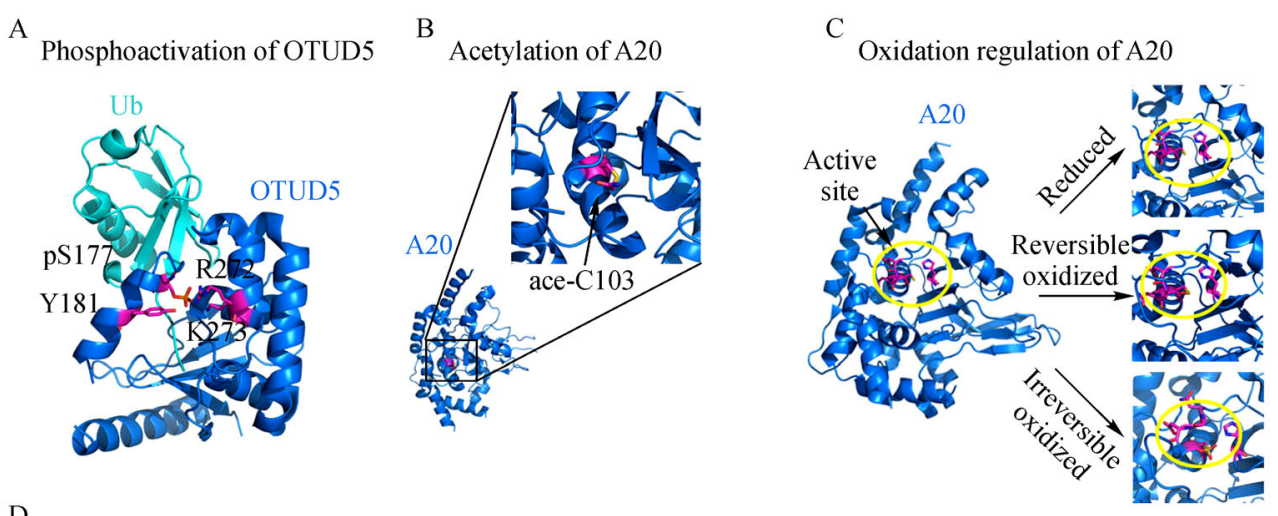

D Allosteric regulation of OTUD7B and OTUB1
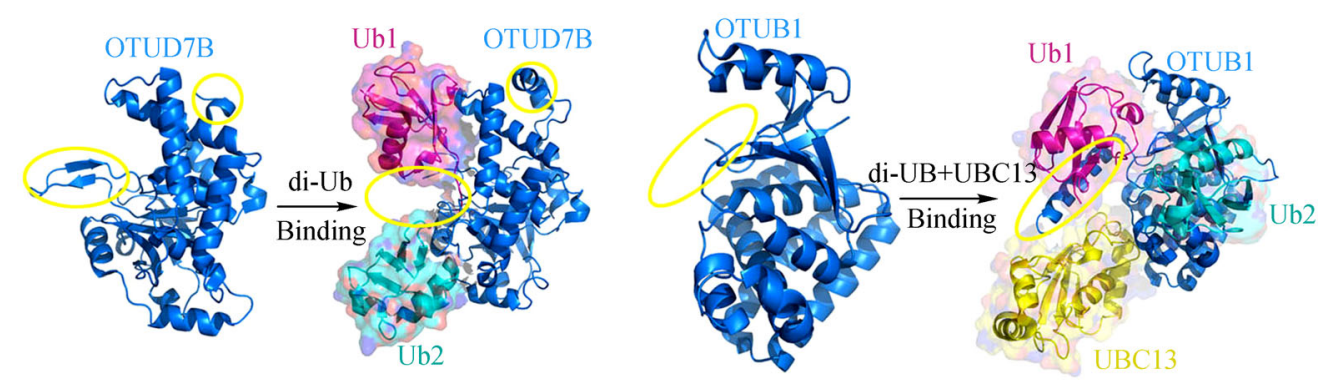

Fig. 6 Structural insights into regulation mechanisms of OTUs activity. (A) Phosphoactivation modification of OTUD5 Ser177 residue (PDB: 3TMP). (B) Acetylation modification of A20 Cys103 residue (PDB: 5V3P). (C) Oxidation regulation of A20 Cys103 in reduced or oxidized station (PDB: 3ZJD, 3ZJE, 3ZJG). (D) Allosteric regulation of OTU7B and OTUB1. Allosteric regulation of OTUD7B by di-Ub binding and OTUB1 by di$\mathrm{Ub}$ and UBC13 binding, the conformation changed remarkably are labeled in yellow cycle (PDB: 5LRW, 5LRV, 2ZFY, 4DHZ).

capabilities and plasticity present in DUBs [7]. Another interesting example of phosphorylation mediated regulation of DUBs function is illustrated by A20. A20 phosphorylation on Ser381 within the zinc-finger region by IKK $\beta$ increases A20 activity toward Lys63-linked chains $[3,46,113,114]$. In addition to directly affecting the catalytic activity of DUBs, phosphorylation can also indirectly regulate DUBs function, for example, by changing the protein subcellular localization. In DNA damage repair, the Ser16-phosphorylated OTUB1 accumulates in the nucleus and impacts the DNA repair [115]. Binding of OTULIN to LUBAC is blocked by OTULIN phosphorylation [76]. Therefore, phosphorylation acts as an important regulator of OTU function by regulating either DUB activity, or its interaction and subcellular localization [116]. Modification of OTUs with ubiquitin or ubiquitin-like molecule constitutes another regulation mode, such as SUMOylation. Taking OTUB2 as an example, SUMOylation of it plays multiple functions: SUMOylation of the last five amino acid residues causes OTUB2 self-inhibition, while SUMOylation of Lys233 mediates OTUB2-YAP/TAZ interaction $[38,49]$.

The OTUs are cysteine proteases, of which reactive site is sensitive to oxidation. Reversible oxidation of the OTUs has also been reported, such as in A20 and OTUD7B regulation [71,117-119]. The A20 structures in different oxidized states revealed how normally unstable hydroxylation intermediates (cysteine sulfenic acid) stabilized by interactions within the OTU domain (Fig. 6C) [71]. Hydrogen peroxide inhibits negative regulation of NF- $\kappa B$ signaling by modifying OTUD7B and thereby impairing its capacity to deubiquitylate receptor interacting protein 1 (RIP1) [120]. Both DUB activity and oxidation require the presence of a low pKa cysteine residue that is created through charge withdrawal by a nearby His residue of the catalytic triad. The cysteine-based OTUs serve as ROS (reactive oxygen species) sensors and the oxidation inhibition regulation is reversible. All these are critical for fine-tuning cellular stress responses. This regulation mechanism provides an attractive model for how ubiquitin signals can be reversibly regulated in response to the reactive oxygen species.

\section{Allosteric regulation}

The specificity and flexibility of substrates, the PTMs modification, and regulated nonfunctional configuration of the natural OTUs, all indicate that allosteric regulation is required to execute OTUs full functionality. The intrinsic DUB activity of catalytic domains is often allosterically modulated by domains within the enzyme or by binding 
partners [22]. Substrate or cofactor binding can regulate enzyme activity, enabling exquisite control of DUB activity. OTULIN chooses the ubiquitin-assisted mechanism to regulate catalytic activity. The crystal structures of OTULIN reveal that DUB activity is directly activated by Met1 diubiquitin [45,108]. By Met1-diubiquitin binding, Glu16 of the proximal ubiquitin resolves an inhibitory conformation and helps with formation of the active catalytic triad. Similarly, OTUD7B activates by Lys11 diubiquitin binding, leading to many more large conformational rearrangements during the catalytic cycle (Fig. 6D) [68].

OTUB1 forms complexes with E2 ubiquitin conjugating enzymes that regulate the activity of both E2 and OTUB1 $[53,121]$. OTUB1 suppresses the ubiquitin conjugating activity of E2, while E2 stimulates OTUB1 DUB activity. Structural studies have elucidated the mechanism of this reciprocal regulation by enzymes that conjugate and remove ubiquitin [122]. Structural studies have revealed that binding of OTUB1 to its E2 conjugate is regulated by the binding of a free ubiquitin monomer to OTUB1, which allosterically regulates the binding power of OTUB1 to E2 enzymes. A comparison between the structures of OTUB1 bound to UBC13, and in the absence of ubiquitin shows that ubiquitin binding triggers conformational change in OTUB1 (Fig. 6D). These structural changes include rearrangements within the OTU domain that maximize contacts with the ubiquitin bound in the OTUB1 proximal site as well as the formation of a roughly 20 residue ubiquitin binding helix in the OTUB1 $\mathrm{N}$ terminus, which is disordered in the state of apo enzyme [123].

Many OTUs contain additional ubiquitin binding domains or motifs, which might directly regulate their activity or specificity. The ubiquitin-chains binding can change the conformation of OTUs and modulate their catalytic activity. OTUD5 requires intact UIMs to efficiently hydrolyse polyubiquitin chains. UIMs can also impart linkage specificity [89]. Many DUBs are activated by UIM binding, which increases the efficiency of substrate capture. For example, A20 binds to multiple ubiquitin binding proteins, including TAX1 binding protein 1 (TAX1BP1) and the A20 binding inhibitor of $\mathrm{NF}-\kappa \mathrm{B}$ activation proteins (ABINs), which may affect catalysis or substrate targeting [124]. Allosteric regulation should be carefully considered in the research of DUB assays and allosteric sites have shown their potential for use in inhibitors design.

\section{Regulation by abundance and subcellular localization}

To understand the function of OTUs on cellular processes, both the individual protein levels and their intracellular locations should be considered. Like most signaling proteins, the quantities of OTUs are regulated by transcription, translation, and degradation. The expression of some OTUs can be induced in a stimulation-dependent manner. One example is the discovery of A20 as a TNFinduced gene. In unstimulated cells, A20 levels are low, but substantially rise upon NF- $\kappa$ B activation, acting as a negative feedback regulator [125]. During proteolytic processing, A20 abundance can be regulated by MALT1 (mucosa associated lymphoid tissue lymphoma translocation protein 1) paracaspase, which cuts $\mathrm{A} 20$ between the $\mathrm{N}$-terminal OTU catalytic domain and the C-terminal UBDs to regulate its function [126]. The cross-regulation of the OTUB1 and E2 enzyme complex in vivo remains to be explored using validated substrates, such as c-IAP1 (cellular inhibitor of apoptosis 1) and the E3 ligase, GRAIL (gene related to anergy in lymphocytes protein) [127].

The subcellular localization of OTUs has several important consequences for their functions. Subcellular localization will determine the palette of substrates available for processing. Many mechanisms can explain DUB subcellular localization, including localization signals, targeting domains, and protein interaction domains that recruit DUBs to defined complexes [128]. Several DUBs show nuclear accumulation, with OTUD7A specifically localizing to the nucleolus, thus regulating its structure and function. Coupling of localization and activation is an important principle of cellular biology. Phosphorylation of OTUB1 by casein kinase 2 keeps OTUB1 in nuclear localization [115,129]. Also, localization can be affected by changing protein interactions. For example, hydroxylation of OTUB1 by FIH (factor inhibiting HIF) alters both the OTUB1 interactome and its substrates $[130,131]$.

\section{Cellular function of OTUs}

OTUs activities fall into several major functional categories: (1) generation of free ubiquitin; (2) reversal of ubiquitin signaling or protein degradation; (3) edit the form of ubiquitin modification. OTUs serve many important cellular functions, and several are essential for cell viability. The importance of the components of the ubiquitin conjugation and deconjugation systems is underscored by the fact that their deregulation has been related to the pathogenesis of a number of human diseases. These include neurodegenerative, inflammation/immunity, apoptosis, cell cycle, and metabolic disorders, as well as cancer $[30,132]$.

\section{OTUs and tumorigenesis}

The wide function of OTUs has a profound impact on the 
regulation of multiple biological processes such as cell cycle control, DNA damage repair, chromatin remodeling, and several cancers related signaling pathways including p53, NF- $\kappa \mathrm{B}$, and Wnt signaling pathways. OTUB1 have important roles in DNA damage repair; A20, OTUD5, OTUD7B, and OTULIN participate in NF- $\kappa$ B signaling pathway; and Trabid are associated with Wnt signaling.

As a tumor suppressor, $\mathrm{p} 53$ performs critical functions in maintaining cellular homeostasis and is frequently mutated in most tumors. Some OTUs are associated with p53 regulation. OTUB1 abrogates p53 ubiquitination, as well as stabilizes and activates p53 in cells. However, this is independent from its deubiquitinating enzyme activity [84,133]. OTUD1 directly suppress p53 ubiquitination in cells. This keeps p53 both stabilized and activated, thus inhibiting cell growth [84]. In the presence of DNA damage or genotoxic stress, OTUD5 regulates p53 stability [62,134].

The NF- $\kappa \mathrm{B}$ signaling pathway has involvement in multiple roles in cancer progression, including antiapoptosis, cell cycle, angiogenesis, and metastasis [135]. A20 and several other DUBs are involved in the NF- $\mathrm{KB}$ signaling pathway $[136,137]$. Through holding the cooperative activity of two ubiquitin-editing domains, A20 downregulates NF- $\kappa \mathrm{B}$ signaling. The N-terminal domain of A20 removes lysine-63 (K63)-linked ubiquitin chains from TRAF6 and RIP1 (receptor interacting protein). A20 has also been reported to possess E3 ligase activity, which adds K48-linked chains to TRAF6 and RIP1 [138]. The Cterminal domain of $\mathrm{A} 20$ is composed of seven $\mathrm{C} 2 / \mathrm{C} 2$ zinc fingers, and functions as an ubiquitin ligase by polyubiquitinating RIP1 with K48-linked ubiquitin chains, thereby targeting RIP1 for proteasomal degradation [94]. Thus A20 can edit ubiquitin chain modification by coordinating removal of K63-linked ubiquitin chains promoting NF- $\kappa \mathrm{B}$ from RIP1. This is followed by its replacement with K48-linked ubiquitin chains that specify degradation. Linear ubiquitin chains generated by LUBAC play an important role in NF- $\kappa$ B activation. By interacting with HOIP, a catalytic subunit of LUBAC, OTULIN synergistically suppresses LUBAC-mediated linear polyubiquitination and NF- $\kappa \mathrm{B}$ activation. The interaction between OTULIN and HOIP is involved in controlling the extent of TNF- $\alpha$ induced NF- $\kappa$ B activation in cells. This is accomplished by fine-tuning the generation of linear ubiquitin chains by LUBAC [139]. Furthermore, OTUD5 deubiquitinates TRAF3, resulting in diminished type I interferon and interleukin 10 responses [140]. A third OTU, OTUD7B, has been implicated in negative regulation of NF- $\kappa B$ signaling. OTUD7B suppresses NF$\kappa \mathrm{B}$ nuclear translocation and transcriptional activity by deubiquitinating RIPK1 signaling intermediaries and interacting with DJ-1 [141,142].

The Wnt signaling pathway is essential for control of embryonic development and is frequently activated in cancer. Trabid is critically involved in T cell factor (TCF)mediated transcription of $W n t$ genes. Recently, Zhu et al. revealed that Trabid inhibits hepatocellular carcinoma growth and metastasis by cleaving RNF8-induced ubiquitination of Twist1 [143].

Multiple DUBs have been classified as oncogenes or tumor suppressors because of their functions involved in tumor development. Therefore, recent studies have focused on DUBs as an anticancer target. However, further understanding of the regulatory mechanisms needs to be investigated for DUBs-targeting therapy against cancer.

\section{OTUs and stem cells}

Post-translational modification by ubiquitin is a key regulator process for stem cell fate determination. Ubiquitination and deubiquitination are the major cellular processes used to balance the protein turnover of several transcription factors that regulate stem cell differentiation $[144,145]$. Cross-regulation between E3 ligases and DUBs for stem cell transcription factors is important in the regulation of stem cell function, including pluripotency, differentiation, and self-renewal. E3 ligases ubiquitinate stem cell-related transcription factors to regulate stem cell differentiation, whereas DUBs maintain those proteins to prevent stem cell differentiation by removing ubiquitin molecules [146,147]. PTEN loss leads to the development of cancer stem cells with the capacity for self-renewal and multi-lineage differentiation [148,149]. Duan et al. found that targeted disruption of PTEN leads to neoplastic transformation of human neural stem cells [149]. Yuan et al. report that, as a deubiquitinase of PTEN, OTUD3 interacts with, deubiquitylates, and stabilizes PTEN [6]. This indicates that the OTUD3-PTEN regulation pathway may play a role in stem cell maintenance and differentiation. Cui et al. report a crucial mechanism of OTUD7B, which regulates the stem cell transcription factor Sox 2 for cell fate determination of NPCs [69]. As a specific DUB for Sox2, OTUD7B maintains NPCs property through the removal of ubiquitin from Sox2. OTUD7B, utilizing its Cterminal ZF-domain, interacts with and stabilizes Sox 2 in a manner dependent on its deubiquitinase activity. More and more studies have uncovered the OTUs regulating function in stem cell pluripotency and differentiation, which may pave the way to improving the treatment of related diseases.

\section{OTUs and DNA repair}

Safeguarding the genome from genotoxic stress is critical for cell survival and for preventing various human diseases. DNA double-strand breaks (DSBs) are lethal lesions that must be repaired. Protein ubiquitination is integral in modulating the repair process [150-152]. The 
ubiquitination events upon DSBs generation are largely mediated by RNF8 and RNF168 on histones, such as H1, $\mathrm{H} 2 \mathrm{~A}, \mathrm{H} 2 \mathrm{AX}$, and H2AZ. Increasing evidence demonstrates the critical function of DUBs such as OTUB1, OTUB2, and OTUD4 in DNA repair, especially in DSBs repair [153]. Protein ubiquitination mediated by the RNF8 E3 ubiquitin ligase recruits DNA DSB response factors and induces chromatin remodeling [154-156]. Kato et al. found that OTUB2 fine-tunes this repair pathway and allows the choice of an adequate DNA repair pathway [50]. OTUB2 suppresses RNF8-mediated L3MBTL1 (lethal (3) malignant brain tumor-like protein 1) ubiquitination and Lys 63-linked ubiquitin chain formation, but not histone H2A ubiquitination. Another otubain subfamily member, OTUB1, suppresses DSB-induced ubiquitination in a different way, by inhibiting the E2-conjugating enzymes in a DUB activity independent manner [5]. OTUD4 has been shown to interact with and stabilize the demethylases ALKBH2 and ALKHBH3, a function which is independent of deubiquitinating activity. In this process, OTUD4 acts as a scaffold, recruits USP7 and USP9X to ALKBH2, and ALKHBH3 for deubiquitination [60].

\section{OTUs and virus infection}

As a host defense mechanism, eukaryotic cells use ubiquitination of microbial molecular patterns to tag invasive pathogens and target them for autophagic degradation. In response to this, intracellular pathogens, such as bacteria or viruses, have developed strategies to hijack the host ubiquitin pathway. One such strategy is to express DUB-like enzymes that are able to counteract ubiquitination and permit pathogens to escape their elimination by autophagy $[157,158]$. Ubiquitination acts a protective modification in anti-viral signaling pathway regulation [159]. Viruses have evolved a series of different mechanisms to evade or subvert cellular processes to their own advantage. To establish a successful infection, viruses utilize DUBs to interfere with both anti-viral immune signaling pathways and other pathways, such as cell cycle and apoptotic pathways [2]. Viruses utilize DUBs to counteract innate immune responses and inhibit anti-viral signaling pathways. Deubiquitination of ubiquitinated signaling molecules from different innate immune signaling pathways by host and viral DUBs ultimately inhibits the synthesis of type I IFN.

Many viral and bacterial pathogens have their own DUBs that are involved in pathogenesis and immune evasion. Many viruses hold OTU domains. Examples include nairoviruses, Crimean-Congo hemorrhagic fever virus (CCHFV), Dugbe virus (DUGV), the papain-like protease (PLP2) domain of the arterivirus equine arteritis virus $(\mathrm{EAV})$, and the protease (PRO) domain of the tymovirus turnip yellow mosaic virus (TYMV) [160]. In
CCHFV, the RNA polymerase as a viral OTU DUB inhibits RIG-I (retinoblastoma-inhibiting gene1) mediated type I IFN synthesis by removing K63-ubiquitin from activated RIG-I [161,162]. In some viruses (EAV, CCHFV), OTUs can hydrolyze both ubiquitin and ISG15, an ubiquitin-like antiviral molecule, from conjugated protein (Fig. 7). Viral OTUs inhibit ISGylation modification of protein in order to counter some type-1 IFN antiviral responses, while DUB activity prevents $\mathrm{TNF} \alpha$ transcriptional effects. By these two conjugation processes, viruses can evade or disrupt many different cellular processes [162-164].

Instead of encoding DUBs directly, some pathogens hijack host DUBs. IAV infection induces host A20 expression, negatively regulating the RIG-I/MDA5 dependent type I IFN signaling pathway [165]. Measles virus infection leads to impaired NF- $\kappa \mathrm{B}$ activation by TLR4 signaling [166]. A20 downregulates NF- $\kappa \mathrm{B}$ mediated gene activation by deubiquitinating K63-ubiquitin TRAF6. TRAF3 and TRAF6 are also deubiquitinated by OTUs (OTUB1 and OTUB2) upon VSV infection of HEK293T cells, negatively regulating RIG-I mediated type I IFN synthesis [167]. In Raji cells (a cell of a cultured line of lymphoblastoid cells derived from a Burkitt lymphoma), EBV infection induces A20 mediated IRF7 deubiquitination to inhibit type I IFN synthesis [168]. Infecting viruses utilize OTUs to inhibit innate-immune antiviral signaling, suggesting that viruses co-evolved with their hosts to acquire similar machinery for tricking immune surveillance and establishing infection [169].

Mounting evidence demonstrates the importance of DUBs, especially OTUs, in viral replication and pathogenesis. It is believed that DUBs will be attractive targets for future antiviral therapeutics. Selective targeting of virus DUBs by small molecule inhibitors or genetics-based technology disruption gives promising potential for antivirals therapeutics and vaccine design [164]. An extensive study to understand more about target-substrate specificity should be considered [169].

\section{OTUs and bone remodeling}

OTUs mediate bone remodeling by regulating both differentiation and function of osteoblasts and osteoclasts [170]. A20 demonstrates the ability to regulate osteoclastogenesis, while knockdown of A20 stimulates bone resorption. A20 expression is increased by intravenous immunoglobulin (IVIG ) treatment and plays an important role in the suppressive effect of IVIG on osteoclast differentiation. LPS is capable of promoting osteoclast differentiation but not activation, through a TNF- $\alpha$ dependent mechanism. Prolonged stimulation with lipopolysaccharide ( LPS) results in the expression of A20, degradation of TRAF6, and inhibition of NF- $\kappa \mathrm{B}$, all of 
A

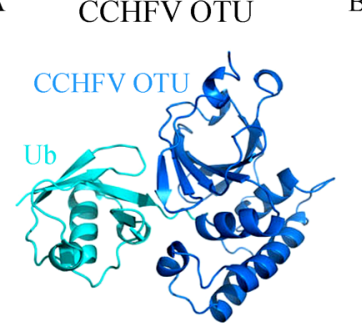

B

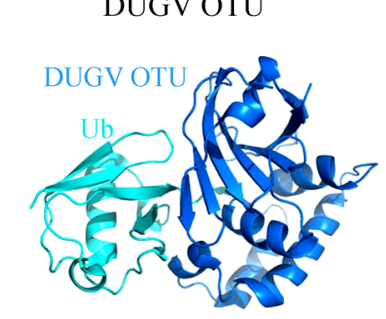

$\mathrm{C}$

\section{EAV PLP2}

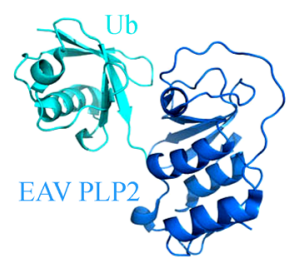

CCHFV OTU-ISG15
D

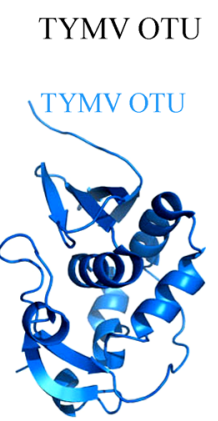

$\mathrm{E}$



F

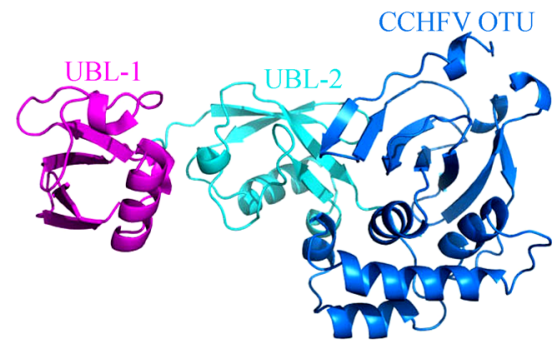

Fig. 7 Structures of viral OTU domains and ISG15. (A-D) Crystal structures of (A) CCHFV viral OTU domain (PDB: 3PT2), (B) DUGV OTU domain (PDB: 4HXD), (C) EAV PLP2 (PDB: 4IUM), (D) TYMV OTU domain (PDB: 4A5U). (E) Crystal structure of ISG15 (PDB: 1Z2M), the Nand C-terminal UBL domain are labeled. (F) Crystal structure of CCHFV OTU-ISG15 complex (PDB: 3PHX).

which lead to a lack of osteoclast resorption [171,172]. Besides A20, OTUB1 is also involved in bone formation through TGF- $\beta$ signaling.

Besides the activities we discussed above, OTUs may play important roles in other fields, but the mechanisms need further study. Yin et al. found that OTUD7A is crucial for the development and function of the CNS. Otud7a null mice show neurodegenerative phenomena, including reduced body weight, developmental delay, abnormal electroencephalography patterns, seizures, reduced ultrasonic vocalizations, decreased grip strength, impaired motor learning/motor coordination, and reduced acoustic startle $[67,100]$. OTUD7A localizes to dendritic spines. The Otud7a null mice have decreased dendritic spine density compared to the wild-type. Nevertheless, OTUD7A plays an important role in regulation of dendritic spine density and activity. Multiple important questions of OTUD7A still need to be answered. These include discovering what specific protein OTUD7A interacts with and regulates as well as in which stages of synapse development OTUD7A is involved.

\section{Outlook and discussion}

Following the approval of the proteasome inhibitor Bortezomib as an anti-cancer therapeutic for the treatment of multiple myeloma, inhibitors of the ubiquitin-proteasome system (UPS ) have been given much attention as potential drug targets for cancer therapy [173]. Despite the significant and growing attractiveness of OTUs as drug targets, OTUs-driven drug discovery has been challenging. A key challenge of these is the similarity and high homology that reduces selectivity. Although many small molecule inhibitors have been reported in publications, few of these have been specific [174]. Secondly, the mechanisms of OTUs enzymes are complex and multilayered. This complexity is found in PTMs, allosteric effects, and substrate-mediated catalysis. Many DUBs can also alternate between active and non-active conformations. All of these factors should be considered during drug development. Thirdly, the ubiquitylation-diubiquitylation process is intracellular, so only traditional small molecular chemicals can reach the DUBs [175]. In spite of the above challenges, researchers have identified some small-molecule inhibitors targeting the DUBs catalytic active center or regulatory region. During the past few decades, we have witnessed great advances in DUB functions, mechanisms of reaction, regulation, and disease linkages. At the same time, there have been major improvements in DUBs biochemical assays and screening technologies, leading to the development of increasing numbers of small molecule DUB inhibitors. Although it is still too early to predict the extent of the broad therapeutic potential of DUBs, the next 
few years of developments of DUB biology and drug discovery will be exciting. The conformational plasticity of the OTU catalytic domain frequently offers both opportunities and targets for selective inhibitor screening [30].

Ubiquitin modification is a key regulator of many cellular physiologic processes. The subfamily of OTUs has emerged as an important regulator of signal pathway cascades. Great progress has been made in the study of OTUs and recent years have seen an explosion in the number of reports addressing mechanisms of regulation and function. However, we still have a way to go to acquire a complete picture of OTUs biology. As we know, PTMs, allosteric, and localization regulation play important roles in OTU activity regulation. More and more evidence shows RNA-OTU association contributing to the DUB enzyme function of OTUs. Ji et al. reveal that RNA plays an active in OTU enzymatic activity as a positive regulator. They reveal that the binding of RNA promotes the formation of OTU granules, highlighting the important regulatory and functional roles of RNA in OTU activity [176]. Another problem is our limited understanding of some OTUs, such as OTUD7A. Evidence shows that OTUD7A is crucial for development and function of the CNS, as well as for the localization of its dendritic spines $[67,100]$. But we still do not know what specific proteins OTUD7A regulates, and interacts with. The mechanism is also unknown. Important questions regarding OTUD7A still need answering. As a potential target, OTUs-focused research will contribute to understanding the pathogenesis of some diseases and will help to lead to improved therapeutic strategies. In this review, we have discussed the structure, substrate specificity, function, and activity regulation mechanism of OTUs. We hope to be helpful in understanding the biological significance and regulation of OTUs [170].

\section{Compliance with ethics guidelines}

Jiansen Du, Lin Fu, Yingli Sui, and Lingqiang Zhang declare that they have no conflict of interest. This manuscript is a review article and does not involve a research protocol requiring approval by the relevant institutional review board or ethics committee.

Open Access This article is licensed under a Creative Commons Attribution 4.0 International License, which permits use, sharing, adaptation, distribution and reproduction in any medium or format, as long as you give appropriate credit to the original author(s) and the source, provide a link to the Creative Commons license, and indicate if changes were made.

The images or other third party material in this article are included in the article's Creative Commons license, unless indicated otherwise in a credit line to the material. If material is not included in the article's Creative Commons license and your intended use is not permitted by statutory regulation or exceeds the permitted use, you will need to obtain permission directly from the copyright holder.

To view a copy of this license, visit http://creativecommons.org/ licenses/by/4.0/.

\section{References}

1. Komander D, Rape M. The ubiquitin code. Annu Rev Biochem 2012; 81(1): 203-229

2. Heideker J, Wertz IE. DUBs, the regulation of cell identity and disease. Biochem J 2015; 467(1): 191

3. Mevissen TE, Hospenthal MK, Geurink PP, Elliott PR, Akutsu M, Arnaudo N, Ekkebus R, Kulathu Y, Wauer T, El Oualid F, Freund SM, Ovaa H, Komander D. OTU deubiquitinases reveal mechanisms of linkage specificity and enable ubiquitin chain restriction analysis. Cell 2013; 154(1): 169-184

4. Swatek KN, Komander D. Ubiquitin modifications. Cell Res 2016; 26(4): 399-422

5. Nakada S, Tai I, Panier S, Al-Hakim A, Iemura S, Juang YC, O’Donnell L, Kumakubo A, Munro M, Sicheri F, Gingras AC, Natsume T, Suda T, Durocher D. Non-canonical inhibition of DNA damage-dependent ubiquitination by OTUB1. Nature 2010; 466(7309): 941-946

6. Yuan L, Lv Y, Li H, Gao H, Song S, Zhang Y, Xing G, Kong X, Wang L, Li Y, Zhou T, Gao D, Xiao ZX, Yin Y, Wei W, He F, Zhang L. Deubiquitylase OTUD3 regulates PTEN stability and suppresses tumorigenesis. Nat Cell Biol 2015; 17(9): 1169-1181

7. Huang OW, Ma X, Yin J, Flinders J, Maurer T, Kayagaki N, Phung Q, Bosanac I, Arnott D, Dixit VM, Hymowitz SG, Starovasnik MA, Cochran AG. Phosphorylation-dependent activity of the deubiquitinase DUBA. Nat Struct Mol Biol 2012; 19(2): 171-175

8. Duy PN, Thuy NT, Trang BK, Giang NH, Van NTH, Xuan NT. Regulation of NF- $\kappa \mathrm{B}-$ and STAT1-mediated plasmacytoid dendritic cell functions by A20. PLoS One 2019; 14(9): e0222697

9. Hu H, Brittain GC, Chang JH, Puebla-Osorio N, Jin J, Zal A, Xiao Y, Cheng X, Chang M, Fu YX, Zal T, Zhu C, Sun SC. OTUD7B controls non-canonical NF- $\kappa \mathrm{B}$ activation through deubiquitination of TRAF3. Nature 2013; 494(7437): 371-374

10. Damgaard RB, Walker JA, Marco-Casanova P, Morgan NV, Titheradge HL, Elliott PR, McHale D, Maher ER, McKenzie ANJ, Komander D. The deubiquitinase OTULIN is an essential negative regulator of inflammation and autoimmunity. Cell 2016; 166(5): $1215-1230 \mathrm{e} 20$

11. Vijay-Kumar S, Bugg CE, Cook WJ. Structure of ubiquitin refined at $1.8 \AA$ resolution. J Mol Biol 1987; 194(3): 531-544

12. Kiel C, Serrano L. The ubiquitin domain superfold: structure-based sequence alignments and characterization of binding epitopes. $\mathrm{J}$ Mol Biol 2006; 355(4): 821-844

13. Walden H, Podgorski MS, Schulman BA. Insights into the ubiquitin transfer cascade from the structure of the activating enzyme for NEDD8. Nature 2003; 422(6929): 330-334

14. Hu M, Li P, Li M, Li W, Yao T, Wu JW, Gu W, Cohen RE, Shi Y. Crystal structure of a UBP-family deubiquitinating enzyme in isolation and in complex with ubiquitin aldehyde. Cell 2002; 111 (7): 1041-1054

15. Reyes-Turcu FE, Horton JR, Mullally JE, Heroux A, Cheng X, 
Wilkinson $\mathrm{KD}$. The ubiquitin binding domain $\mathrm{ZnF}$ UBP recognizes the C-terminal diglycine motif of unanchored ubiquitin. Cell 2006; 124(6): 1197-1208

16. Yau R, Rape M. The increasing complexity of the ubiquitin code. Nat Cell Biol 2016; 18(6): 579-586

17. Peng J, Schwartz D, Elias JE, Thoreen CC, Cheng D, Marsischky G, Roelofs J, Finley D, Gygi SP. A proteomics approach to understanding protein ubiquitination. Nat Biotechnol 2003; 21(8): 921-926

18. Xu P, Duong DM, Seyfried NT, Cheng D, Xie Y, Robert J, Rush J, Hochstrasser M, Finley D, Peng J. Quantitative proteomics reveals the function of unconventional ubiquitin chains in proteasomal degradation. Cell 2009; 137(1): 133-145

19. Swaney DL, Beltrao P, Starita L, Guo A, Rush J, Fields S, Krogan NJ, Villén J. Global analysis of phosphorylation and ubiquitylation cross-talk in protein degradation. Nat Methods 2013; 10(7): 676682

20. Ohtake F, Saeki Y, Sakamoto K, Ohtake K, Nishikawa H, Tsuchiya H, Ohta T, Tanaka K, Kanno J. Ubiquitin acetylation inhibits polyubiquitin chain elongation. EMBO Rep 2015; 16(2): 192-201

21. Cui J, Yao Q, Li S, Ding X, Lu Q, Mao H, Liu L, Zheng N, Chen S, Shao F. Glutamine deamidation and dysfunction of ubiquitin/ NEDD8 induced by a bacterial effector family. Science 2010; 329 (5996): 1215-1218

22. Mevissen TET, Komander D. Mechanisms of deubiquitinase specificity and regulation. Annu Rev Biochem 2017; 86(1): 159192

23. Schulman BA, Harper JW. Ubiquitin-like protein activation by E1 enzymes: the apex for downstream signalling pathways. Nat Rev Mol Cell Biol 2009; 10(5): 319-331

24. Ye Y, Rape M. Building ubiquitin chains: E2 enzymes at work. Nat Rev Mol Cell Biol 2009; 10(11): 755-764

25. Buetow L, Huang DT. Structural insights into the catalysis and regulation of E3 ubiquitin ligases. Nat Rev Mol Cell Biol 2016; 17(10): 626-642

26. Clague MJ, Barsukov I, Coulson JM, Liu H, Rigden DJ, Urbé S. Deubiquitylases from genes to organism. Physiol Rev 2013; 93(3): 1289-1315

27. Komander D, Clague MJ, Urbé S. Breaking the chains: structure and function of the deubiquitinases. Nat Rev Mol Cell Biol 2009; 10(8): 550-563

28. Reyes-Turcu FE, Ventii KH, Wilkinson KD. Regulation and cellular roles of ubiquitin-specific deubiquitinating enzymes. Annu Rev Biochem 2009; 78(1): 363-397

29. Amerik AY, Hochstrasser M. Mechanism and function of deubiquitinating enzymes. Biochim Biophys Acta 2004; 1695(13): 189-207

30. Clague MJ, Urbé S, Komander D. Breaking the chains: deubiquitylating enzyme specificity begets function. Nat Rev Mol Cell Biol 2019; 20(6): 338-352

31. Ye Y, Blaser G, Horrocks MH, Ruedas-Rama MJ, Ibrahim S, Zhukov AA, Orte A, Klenerman D, Jackson SE, Komander D. Ubiquitin chain conformation regulates recognition and activity of interacting proteins. Nature 2012; 492(7428): 266-270

32. Renatus M, Parrado SG, D’Arcy A, Eidhoff U, Gerhartz B, Hassiepen U, Pierrat B, Riedl R, Vinzenz D, Worpenberg S,
Kroemer M. Structural basis of ubiquitin recognition by the deubiquitinating protease USP2. Structure 2006; 14(8): 12931302

33. Schaefer JB, Morgan DO. Protein-linked ubiquitin chain structure restricts activity of deubiquitinating enzymes. J Biol Chem 2011; 286(52): 45186-45196

34. Clague MJ, Coulson JM, Urbé S. Cellular functions of the DUBs. J Cell Sci 2012; 125(Pt 2): 277-286

35. Makarova KS, Aravind L, Koonin EV. A novel superfamily of predicted cysteine proteases from eukaryotes, viruses and Chlamydia pneumoniae. Trends Biochem Sci 2000; 25(2): 50-52

36. Rodesch C, Geyer PK, Patton JS, Bae E, Nagoshi RN. Developmental analysis of the ovarian tumor gene during Drosophila oogenesis. Genetics 1995; 141(1): 191-202

37. Sass GL, Comer AR, Searles LL. The ovarian tumor protein isoforms of Drosophila melanogaster exhibit differences in function, expression, and localization. Dev Biol 1995; 167(1): 201-212

38. Balakirev MY, Tcherniuk SO, Jaquinod M, Chroboczek J. Otubains: a new family of cysteine proteases in the ubiquitin pathway. EMBO Rep 2003; 4(5): 517-522

39. Nanao MH, Tcherniuk SO, Chroboczek J, Dideberg O, Dessen A, Balakirev MY. Crystal structure of human otubain 2. EMBO Rep 2004; 5(8): 783-788

40. Lin SC, Chung JY, Lamothe B, Rajashankar K, Lu M, Lo YC, Lam AY, Darnay BG, Wu H. Molecular basis for the unique deubiquitinating activity of the NF- $\mathrm{KB}$ inhibitor A20. J Mol Biol 2008; 376(2): 526-540

41. Kulathu Y. Novel diubiquitin probes expand the chemical toolkit to study DUBs. Cell Chem Biol 2016; 23(4): 432-434

42. Edelmann MJ, Iphöfer A, Akutsu M, Altun M, di Gleria K, Kramer HB, Fiebiger E, Dhe-Paganon S, Kessler BM. Structural basis and specificity of human otubain 1-mediated deubiquitination. Biochem J 2009; 418(2): 379-390

43. Wang T, Yin L, Cooper EM, Lai MY, Dickey S, Pickart CM, Fushman D, Wilkinson KD, Cohen RE, Wolberger C. Evidence for bidentate substrate binding as the basis for the K48 linkage specificity of otubain 1. J Mol Biol 2009; 386(4): 1011-1023

44. Licchesi JD, Mieszczanek J, Mevissen TE, Rutherford TJ, Akutsu M, Virdee S, El Oualid F, Chin JW, Ovaa H, Bienz M, Komander D. An ankyrin-repeat ubiquitin-binding domain determines TRABID's specificity for atypical ubiquitin chains. Nat Struct Mol Biol 2012; 19(1): 62-71

45. Keusekotten K, Elliott PR, Glockner L, Fiil BK, Damgaard RB, Kulathu Y, Wauer T, Hospenthal MK, Gyrd-Hansen M, Krappmann D, Hofmann K, Komander D. OTULIN antagonizes LUBAC signaling by specifically hydrolyzing Met1-linked polyubiquitin. Cell 2013; 153(6): 1312-1326

46. Komander D, Barford D. Structure of the A20 OTU domain and mechanistic insights into deubiquitination. Biochem J 2008; 409(1): 77-85

47. Boudreaux DA, Chaney J, Maiti TK, Das C. Contribution of active site glutamine to rate enhancement in ubiquitin C-terminal hydrolases. FEBS J 2012; 279(6): 1106-1118

48. Storer AC, Ménard R. Catalytic mechanism in papain family of cysteine peptidases. Methods Enzymol 1994; 244: 486-500

49. Zhang Z, Du J, Wang S, Shao L, Jin K, Li F, Wei B, Ding W, Fu P, 
van Dam H, Wang A, Jin J, Ding C, Yang B, Zheng M, Feng XH, Guan KL, Zhang L. OTUB2 promotes cancer metastasis via Hippo-independent activation of YAP and TAZ. Mol Cell 2019; 73(1): 7-21.e7

50. Kato K, Nakajima K, Ui A, Muto-Terao Y, Ogiwara H, Nakada S. Fine-tuning of DNA damage-dependent ubiquitination by OTUB2 supports the DNA repair pathway choice. Mol Cell 2014; 53(4): 617-630

51. Li Y, Yang JY, Xie X, Jie Z, Zhang L, Shi J, Lin D, Gu M, Zhou X, Li HS, Watowich SS, Jain A, Yun Jung S, Qin J, Cheng X, Sun SC. Preventing abnormal NF- $\kappa \mathrm{B}$ activation and autoimmunity by Otub1-mediated p100 stabilization. Cell Res 2019; 29(6): 474-485

52. Zhou X, Yu J, Cheng X, Zhao B, Manyam GC, Zhang L, Schluns K, Li P, Wang J, Sun SC. The deubiquitinase Otub1 controls the activation of $\mathrm{CD}^{+} \mathrm{T}$ cells and NK cells by regulating IL-15mediated priming. Nat Immunol 2019; 20(7): 879-889

53. Wiener R, Zhang X, Wang $\mathrm{T}$, Wolberger $\mathrm{C}$. The mechanism of OTUB1-mediated inhibition of ubiquitination. Nature 2012; 483(7391): 618-622

54. Zhang Z, Fan Y, Xie F, Zhou H, Jin K, Shao L, Shi W, Fang P, Yang B, van Dam H, Ten Dijke P, Zheng X, Yan X, Jia J, Zheng M, Jin J, Ding C, Ye S, Zhou F, Zhang L. Breast cancer metastasis suppressor OTUD1 deubiquitinates SMAD7. Nat Commun 2017; 8(1): 2116

55. Yao F, Xiao Z, Sun Y, Ma L. SKP2 and OTUD1 govern nonproteolytic ubiquitination of YAP that promotes YAP nuclear localization and activity. Cell Stress 2018; 2(9): 233-235

56. Kim Y, Kim W, Song Y, Kim JR, Cho K, Moon H, Ro SW, Seo E, Ryu YM, Myung SJ, Jho EH. Deubiquitinase YOD1 potentiates YAP/TAZ activities through enhancing ITCH stability. Proc Natl Acad Sci USA 2017; 114(18): 4691-4696

57. Schimmack G, Schorpp K, Kutzner K, Gehring T, Brenke JK, Hadian K, Krappmann D. YOD1/TRAF6 association balances p62-dependent IL-1 signaling to NF-кB. eLife 2017; 6: e22416.

58. Zou J, Ma W, Li J, Littlejohn R, Zhou H, Kim IM, Fulton DJR, Chen W, Weintraub NL, Zhou J, Su H. Neddylation mediates ventricular chamber maturation through repression of Hippo signaling. Proc Natl Acad Sci USA 2018; 115(17): E4101-E4110

59. Du T, Li H, Fan Y, Yuan L, Guo X, Zhu Q, Yao Y, Li X, Liu C, Yu X, Liu Z, Cui CP, Han C, Zhang L. The deubiquitylase OTUD3 stabilizes GRP78 and promotes lung tumorigenesis. Nat Commun 2019; 10(1): 2914

60. Zhao Y, Majid MC, Soll JM, Brickner JR, Dango S, Mosammaparast $\mathrm{N}$. Noncanonical regulation of alkylation damage resistance by the OTUD4 deubiquitinase. EMBO J 2015; 34(12): 1687-1703

61. Zhao Y, Mudge MC, Soll JM, Rodrigues RB, Byrum AK, Schwarzkopf EA, Bradstreet TR, Gygi SP, Edelson BT, Mosammaparast N. OTUD4 is a phospho-activated K63 deubiquitinase that regulates MyD88-dependent signaling. Mol Cell 2018; 69(3): 505-516.e5

62. Park SY, Choi HK, Choi Y, Kwak S, Choi KC, Yoon HG. Deubiquitinase OTUD5 mediates the sequential activation of PDCD5 and p53 in response to genotoxic stress. Cancer Lett 2015; 357(1): 419-427

63. Li F, Sun Q, Liu K, Han H, Lin N, Cheng Z, Cai Y, Tian F, Mao Z, Tong T, Zhao W. The deubiquitinase OTUD5 regulates Ku80 stability and non-homologous end joining. Cell Mol Life Sci 2019;
76(19): 3861-3873

64. Kim SY, Kwon SK, Lee SY, Baek KH. Ubiquitin-specific peptidase 5 and ovarian tumor deubiquitinase $6 \mathrm{~A}$ are differentially expressed in p53 ${ }^{+/+}$and p53 $3^{-/}$HCT116 cells. Int J Oncol 2018 Mar 5. [Epub ahead of print] doi: 10.3892/ijo.2018.4302

65. Sobol A, Askonas C, Alani S, Weber MJ, Ananthanarayanan V, Osipo C, Bocchetta M. Deubiquitinase OTUD6B isoforms are important regulators of growth and proliferation. Mol Cancer Res 2017; 15(2): 117-127

66. Xu Z, Pei L, Wang L, Zhang F, Hu X, Gui Y. Snail1-dependent transcriptional repression of Cezanne2 in hepatocellular carcinoma. Oncogene 2014; 33(22): 2836-2845

67. Uddin M, Unda BK, Kwan V, Holzapfel NT, White SH, Chalil L, Woodbury-Smith M, Ho KS, Harward E, Murtaza N, Dave B, Pellecchia G, D'Abate L, Nalpathamkalam T, Lamoureux S, Wei J, Speevak M, Stavropoulos J, Hope KJ, Doble BW, Nielsen J, Wassman ER, Scherer SW, Singh KK. OTUD7A regulates neurodevelopmental phenotypes in the $15 \mathrm{q} 13.3$ microdeletion syndrome. Am J Hum Genet 2018; 102(2): 278-295

68. Mevissen TET, Kulathu Y, Mulder MPC, Geurink PP, Maslen SL, Gersch M, Elliott PR, Burke JE, van Tol BDM, Akutsu M, Oualid FE, Kawasaki M, Freund SMV, Ovaa H, Komander D. Molecular basis of Lys11-polyubiquitin specificity in the deubiquitinase Cezanne. Nature 2016; 538(7625): 402-405

69. Cui CP, Zhang Y, Wang C, Yuan F, Li H, Yao Y, Chen Y, Li C, Wei W, Liu CH, He F, Liu Y, Zhang L. Dynamic ubiquitylation of Sox2 regulates proteostasis and governs neural progenitor cell differentiation. Nat Commun 2018; 9(1): 4648

70. Lin DD, Shen Y, Qiao S, Liu WW, Zheng L, Wang YN, Cui N, Wang YF, Zhao S, Shi JH. Upregulation of OTUD7B (Cezanne) promotes tumor progression via AKT/VEGF pathway in lung squamous carcinoma and adenocarcinoma. Front Oncol 2019; 9: 862

71. Kulathu Y, Garcia FJ, Mevissen TE, Busch M, Arnaudo N, Carroll KS, Barford D, Komander D. Regulation of A20 and other OTU deubiquitinases by reversible oxidation. Nat Commun 2013; 4(1): 1569

72. Tokunaga F, Nishimasu H, Ishitani R, Goto E, Noguchi T, Mio K, Kamei K, Ma A, Iwai K, Nureki O. Specific recognition of linear polyubiquitin by A20 zinc finger 7 is involved in NF- $\kappa$ B regulation. EMBO J 2012; 31(19): 3856-3870

73. Bosanac I, Wertz IE, Pan B, Yu C, Kusam S, Lam C, Phu L, Phung Q, Maurer B, Arnott D, Kirkpatrick DS, Dixit VM, Hymowitz SG. Ubiquitin binding to A20 $\mathrm{ZnF} 4$ is required for modulation of NF$\kappa \mathrm{B}$ signaling. Mol Cell 2010; 40(4): 548-557

74. Michel MA, Elliott PR, Swatek KN, Simicek M, Pruneda JN, Wagstaff JL, Freund SM, Komander D. Assembly and specific recognition of k29- and k33-linked polyubiquitin. Mol Cell 2015; 58(1): 95-109

75. Zhu Y, Qu C, Hong X, Jia Y, Lin M, Luo Y, Lin F, Xie X, Xie X, Huang J, Wu Q, Qiu X, Piao D, Xing Y, Yu T, Lu Y, Huang Q, Yu C, Jin J, Zhang Z. Trabid inhibits hepatocellular carcinoma growth and metastasis by cleaving RNF8-induced K63 ubiquitination of Twist1. Cell Death Differ 2019; 26(2): 306-320

76. Elliott PR, Nielsen SV, Marco-Casanova P, Fiil BK, Keusekotten K, Mailand N, Freund SM, Gyrd-Hansen M, Komander D. Molecular basis and regulation of OTULIN-LUBAC interaction. 
Mol Cell 2014; 54(3): 335-348

77. Weber A, Elliott PR, Pinto-Fernandez A, Bonham S, Kessler BM, Komander D, El Oualid F, Krappmann D. A linear diubiquitinbased probe for efficient and selective detection of the deubiquitinating enzyme OTULIN. Cell Chem Biol 2017; 24(10): 12991313.e7

78. Zhao M, Song K, Hao W, Wang L, Patil G, Li Q, Xu L, Hua F, Fu B, Schwamborn JC, Dorf ME, Li S. Non-proteolytic ubiquitination of OTULIN regulates NF- $\kappa \mathrm{B}$ signaling pathway. J Mol Cell Biol 2019; mjz081

79. Tsai YC, Kotiya A, Kiris E, Yang M, Bavari S, Tessarollo L, Oyler GA, Weissman AM. Deubiquitinating enzyme VCIP135 dictates the duration of botulinum neurotoxin type A intoxication. Proc Natl Acad Sci USA 2017; 114(26): E5158-E5166

80. Zhang X, Zhang H, Wang Y. Phosphorylation regulates VCIP135 function in Golgi membrane fusion during the cell cycle. J Cell Sci 2014; 127(Pt 1): 172-181

81. Gao P, Wang F, Huo J, Wan D, Zhang J, Niu J, Wu J, Yu B, Sun T. ALG13 deficiency associated with increased seizure susceptibility and severity. Neuroscience 2019; 409: 204-221

82. Lin SC, Chung JY, Lamothe B, Rajashankar K, Lu M, Lo YC, Lam AY, Darnay BG, Wu H. Molecular basis for the unique deubiquitinating activity of the NF- $\mathrm{kB}$ inhibitor A20. J Mol Biol 2008; 376(2): 526-540

83. Zhao L, Wang X, Yu Y, Deng L, Chen L, Peng X, Jiao C, Gao G, Tan X, Pan W, Ge X, Wang P. OTUB1 protein suppresses mTOR complex 1 (mTORC1) activity by deubiquitinating the mTORC1 inhibitor DEPTOR. J Biol Chem 2018; 293(13): 4883-4892

84. Piao S, Pei HZ, Huang B, Baek SH. Ovarian tumor domaincontaining protein 1 deubiquitinates and stabilizes p53. Cell Signal 2017; 33: 22-29

85. Zhang L, Liu J, Qian L, Feng Q, Wang X, Yuan Y, Zuo Y, Cheng Q, Miao Y, Guo T, Zheng X, Zheng H. Induction of OTUD1 by RNA viruses potently inhibits innate immune responses by promoting degradation of the MAVS/TRAF3/TRAF6 signalosome. PLoS Pathog 2018; 14(5): e1007067

86. Ernst R, Mueller B, Ploegh HL, Schlieker C. The otubain YOD1 is a deubiquitinating enzyme that associates with p97 to facilitate protein dislocation from the ER. Mol Cell 2009; 36(1): 28-38

87. Papadopoulos C, Kirchner P, Bug M, Grum D, Koerver L, Schulze N, Poehler R, Dressler A, Fengler S, Arhzaouy K, Lux V, Ehrmann M, Weihl CC, Meyer H. VCP/p97 cooperates with YOD1, UBXD1 and PLAA to drive clearance of ruptured lysosomes by autophagy. EMBO J 2017; 36(2): 135-150

88. Das R, Schwintzer L, Vinopal S, Aguado Roca E, Sylvester M, Oprisoreanu AM, Schoch S, Bradke F, Broemer M. New roles for the de-ubiquitylating enzyme OTUD4 in an RNA-protein network and RNA granules. J Cell Sci 2019; 132(12): jcs229252

89. Kayagaki N, Phung Q, Chan S, Chaudhari R, Quan C, O'Rourke KM, Eby M, Pietras E, Cheng G, Bazan JF, Zhang Z, Arnott D, Dixit VM. DUBA: a deubiquitinase that regulates type I interferon production. Science 2007; 318(5856): 1628-1632

90. de Vivo A, Sanchez A, Yegres J, Kim J, Emly S, Kee Y. The OTUD5-UBR5 complex regulates FACT-mediated transcription at damaged chromatin. Nucleic Acids Res 2019; 47(2): 729-746

91. Santiago-Sim T, Burrage LC, Ebstein F, Tokita MJ, Miller M, Bi W, Braxton AA, Rosenfeld JA, Shahrour M, Lehmann A, Cogné
B, Küry S, Besnard T, Isidor B, Bézieau S, Hazart I, Nagakura H, Immken LL, Littlejohn RO, Roeder E; EuroEPINOMICS RES Consortium Autosomal Recessive working group, S. Hande Caglayan, Kara B, Hardies K, Weckhuysen S, May P, Lemke JR, Elpeleg O, Abu-Libdeh B, James KN, Silhavy JL, Issa MY, Zaki MS, Gleeson JG, Seavitt JR, Dickinson ME, Ljungberg MC, Wells S, Johnson SJ, Teboul L, Eng CM, Yang Y, Kloetzel PM, Heaney JD, Walkiewicz MA, Afawi Z, Balling R, Barisic N, Baulac S, Craiu D, De Jonghe P, Guerrero-Lopez R, Guerrini R, Helbig I, Hjalgrim H, Jähn J, Klein KM, Leguern E, Lerche H, Marini C, Muhle H, Rosenow F, Serratosa J, Sterbová K, Suls A, Moller RS, Striano P, Weber Y, Zara F. Biallelic variants in OTUD6B cause an intellectual disability syndrome associated with seizures and dysmorphic features. Am J Hum Genet 2017; 100(4): 676-688

92. Takata M, Pachera E, Frank-Bertoncelj M, Kozlova A, Jüngel A, Whitfield ML, Assassi S, Calcagni M, de Vries-Bouwstra J, Huizinga TW, Kurreeman F, Kania G, Distler O. OTUD6B-AS1 might be a novel regulator of apoptosis in systemic sclerosis. Front Immunol 2019; 10: 1100

93. Wang G, Zhang ZJ, Jian WG, Liu PH, Xue W, Wang TD, Meng YY, Yuan C, Li HM, Yu YP, Liu ZX, Wu Q, Zhang DM, Zhang C. Novel long noncoding RNA OTUD6B-AS1 indicates poor prognosis and inhibits clear cell renal cell carcinoma proliferation via the Wnt/ß-catenin signaling pathway. Mol Cancer 2019; 18(1): 15

94. Wertz IE, O'Rourke KM, Zhou H, Eby M, Aravind L, Seshagiri S, Wu P, Wiesmann C, Baker R, Boone DL, Ma A, Koonin EV, Dixit VM. De-ubiquitination and ubiquitin ligase domains of A20 downregulate NF-kB signalling. Nature 2004; 430(7000): 694699

95. Mauro C, Pacifico F, Lavorgna A, Mellone S, Iannetti A, Acquaviva R, Formisano S, Vito P, Leonardi A. ABIN-1 binds to NEMO/IKK $\gamma$ and co-operates with A20 in inhibiting NF- $\mathrm{KB}$. J Biol Chem 2006; 281(27): 18482-18488

96. Skaug B, Chen J, Du F, He J, Ma A, Chen ZJ. Direct, noncatalytic mechanism of IKK inhibition by A20. Mol Cell 2011; 44(4): 559571

97. Düwel M, Welteke V, Oeckinghaus A, Baens M, Kloo B, Ferch U, Darnay BG, Ruland J, Marynen P, Krappmann D. A20 negatively regulates $\mathrm{T}$ cell receptor signaling to $\mathrm{NF}-\kappa \mathrm{B}$ by cleaving Malt1 ubiquitin chains. J Immunol 2009; 182(12): 7718-7728

98. Li L, Soetandyo N, Wang Q, Ye Y. The zinc finger protein A20 targets TRAF2 to the lysosomes for degradation. Biochim Biophys Acta 2009; 1793(2): 346-353

99. Yang C, Zang W, Tang Z, Ji Y, Xu R, Yang Y, Luo A, Hu B, Zhang Z, Liu Z, Zheng X. A20/TNFAIP3 regulates the DNA damage response and mediates tumor cell resistance to DNA-damaging therapy. Cancer Res 2018; 78(4): 1069-1082

100. Yin J, Chen W, Chao ES, Soriano S, Wang L, Wang W, Cummock SE, Tao H, Pang K, Liu Z, Pereira FA, Samaco RC, Zoghbi HY, Xue M, Schaaf CP. Otud7a knockout mice recapitulate many neurological features of $15 \mathrm{q} 13.3$ microdeletion syndrome. Am J Hum Genet 2018; 102(2): 296-308

101. Bremm A, Moniz S, Mader J, Rocha S, Komander D. Cezanne (OTUD7B) regulates HIF-1 $\alpha$ homeostasis in a proteasomeindependent manner. EMBO Rep 2014; 15(12): 1268-1277 
102. Wang B, Jie Z, Joo D, Ordureau A, Liu P, Gan W, Guo J, Zhang J, North BJ, Dai X, Cheng X, Bian X, Zhang L, Harper JW, Sun SC, Wei W. TRAF2 and OTUD7B govern a ubiquitin-dependent switch that regulates mTORC2 signalling. Nature 2017; 545 (7654): 365-369

103. Luong A, Fragiadaki M, Smith J, Boyle J, Lutz J, Dean JL, Harten S, Ashcroft M, Walmsley SR, Haskard DO, Maxwell PH, Walczak $\mathrm{H}$, Pusey C, Evans PC. Cezanne regulates inflammatory responses to hypoxia in endothelial cells by targeting TRAF6 for deubiquitination. Circ Res 2013; 112(12): 1583-1591

104. Tran H, Hamada F, Schwarz-Romond T, Bienz M. Trabid, a new positive regulator of Wnt-induced transcription with preference for binding and cleaving K63-linked ubiquitin chains. Genes Dev 2008; 22(4): 528-542

105. Bai SW, Herrera-Abreu MT, Rohn JL, Racine V, Tajadura V, Suryavanshi N, Bechtel S, Wiemann S, Baum B, Ridley AJ. Identification and characterization of a set of conserved and new regulators of cytoskeletal organization, cell morphology and migration. BMC Biol 2011; 9(1): 54

106. Jin J, Xie X, Xiao Y, Hu H, Zou Q, Cheng X, Sun SC. Epigenetic regulation of the expression of I112 and Il23 and autoimmune inflammation by the deubiquitinase Trabid. Nat Immunol 2016; 17(3): 259-268

107. Afonina IS, Beyaert R. Trabid epigenetically drives expression of IL-12 and IL-23. Nat Immunol 2016; 17(3): 227-228

108. Rivkin E, Almeida SM, Ceccarelli DF, Juang YC, MacLean TA, Srikumar T, Huang H, Dunham WH, Fukumura R, Xie G, Gondo Y, Raught B, Gingras AC, Sicheri F, Cordes SP. The linear ubiquitin-specific deubiquitinase gumby regulates angiogenesis. Nature 2013; 498(7454): 318-324

109. Zhou Q, Yu X, Demirkaya E, Deuitch N, Stone D, Tsai WL, Kuehn HS, Wang H, Yang D, Park YH, Ombrello AK, Blake M, Romeo T, Remmers EF, Chae JJ, Mullikin JC, Güzel F, Milner JD, Boehm M, Rosenzweig SD, Gadina M, Welch SB, Özen S, Topaloglu R, Abinun M, Kastner DL, Aksentijevich I. Biallelic hypomorphic mutations in a linear deubiquitinase define otulipenia, an earlyonset autoinflammatory disease. Proc Natl Acad Sci USA 2016; 113(36): 10127-10132

110. Hrdinka M, Gyrd-Hansen M. The Met1-linked ubiquitin machinery: emerging themes of (de)regulation. Mol Cell 2017; 68(2): 265-280

111. Heger K, Wickliffe KE, Ndoja A, Zhang J, Murthy A, Dugger DL, Maltzman A, de Sousa E Melo F, Hung J, Zeng Y, Verschueren E, Kirkpatrick DS, Vucic D, Lee WP, Roose-Girma M, Newman RJ, Warming S, Hsiao YC, Kőmüves LG, Webster JD, Newton K, Dixit VM. OTULIN limits cell death and inflammation by deubiquitinating LUBAC. Nature 2018; 559(7712): 120-124

112. Rutz S, Kayagaki N, Phung QT, Eidenschenk C, Noubade R, Wang X, Lesch J, Lu R, Newton K, Huang OW, Cochran AG, Vasser M, Fauber BP, DeVoss J, Webster J, Diehl L, Modrusan Z, Kirkpatrick DS, Lill JR, Ouyang W, Dixit VM. Deubiquitinase DUBA is a post-translational brake on interleukin-17 production in $\mathrm{T}$ cells. Nature 2015; 518(7539): 417-421

113. Wertz IE, Newton K, Seshasayee D, Kusam S, Lam C, Zhang J, Popovych N, Helgason E, Schoeffler A, Jeet S, Ramamoorthi N, Kategaya L, Newman RJ, Horikawa K, Dugger D, Sandoval W, Mukund S, Zindal A, Martin F, Quan C, Tom J, Fairbrother WJ,
Townsend M, Warming S, DeVoss J, Liu J, Dueber E, Caplazi P, Lee WP, Goodnow CC, Balazs M, Yu K, Kolumam G, Dixit VM. Phosphorylation and linear ubiquitin direct A20 inhibition of inflammation. Nature 2015; 528(7582): 370-375

114. Hutti JE, Turk BE, Asara JM, Ma A, Cantley LC, Abbott DW. IкB kinase $\beta$ phosphorylates the K63 deubiquitinase A20 to cause feedback inhibition of the NF-kB pathway. Mol Cell Biol 2007; 27 (21): 7451-7461

115. Herhaus L, Perez-Oliva AB, Cozza G, Gourlay R, Weidlich S, Campbell DG, Pinna LA, Sapkota GP. Casein kinase 2 (CK2) phosphorylates the deubiquitylase OTUB1 at Ser16 to trigger its nuclear localization. Sci Signal 2015; 8(372): ra35

116. Leznicki P, Kulathu Y. Mechanisms of regulation and diversification of deubiquitylating enzyme function. J Cell Sci 2017; 130(12): 1997-2006

117. Cotto-Rios XM, Békés M, Chapman J, Ueberheide B, Huang TT. Deubiquitinases as a signaling target of oxidative stress. Cell Reports 2012; 2(6): 1475-1484

118. Lee JG, Baek K, Soetandyo N, Ye Y. Reversible inactivation of deubiquitinases by reactive oxygen species in vitro and in cells. Nat Commun 2013; 4(1): 1568

119. Ross SH, Lindsay Y, Safrany ST, Lorenzo O, Villa F, Toth R, Clague MJ, Downes CP, Leslie NR. Differential redox regulation within the PTP superfamily. Cell Signal 2007; 19(7): 1521-1530

120. Enesa K, Ito K, Luong A, Thorbjornsen I, Phua C, To Y, Dean J, Haskard DO, Boyle J, Adcock I, Evans PC. Hydrogen peroxide prolongs nuclear localization of NF- $\mathrm{KB}$ in activated cells by suppressing negative regulatory mechanisms. J Biol Chem 2008; 283(27): 18582-18590

121. Wiener R, DiBello AT, Lombardi PM, Guzzo CM, Zhang X, Matunis MJ, Wolberger C. E2 ubiquitin-conjugating enzymes regulate the deubiquitinating activity of OTUB1. Nat Struct Mol Biol 2013; 20(9): 1033-1039

122. Juang YC, Landry MC, Sanches M, Vittal V, Leung CC, Ceccarelli DF, Mateo AR, Pruneda JN, Mao DY, Szilard RK, Orlicky S, Munro M, Brzovic PS, Klevit RE, Sicheri F, Durocher D. OTUB1 co-opts Lys48-linked ubiquitin recognition to suppress E2 enzyme function. Mol Cell 2012; 45(3): 384-397

123. Sato Y, Yamagata A, Goto-Ito S, Kubota K, Miyamoto R, Nakada S, Fukai S. Molecular basis of Lys-63-linked polyubiquitination inhibition by the interaction between human deubiquitinating enzyme OTUB1 and ubiquitin-conjugating enzyme UBC13. J Biol Chem 2012; 287(31): 25860-25868

124. Iha H, Peloponese JM, Verstrepen L, Zapart G, Ikeda F, Smith CD, Starost MF, Yedavalli V, Heyninck K, Dikic I, Beyaert R, Jeang $\mathrm{KT}$. Inflammatory cardiac valvulitis in TAX1BP1-deficient mice through selective NF-kB activation. EMBO J 2008; 27(4): 629641

125. Hymowitz SG, Wertz IE. A20: from ubiquitin editing to tumour suppression. Nat Rev Cancer 2010; 10(5): 332-341

126. Coornaert B, Baens M, Heyninck K, Bekaert T, Haegman M, Staal J, Sun L, Chen ZJ, Marynen P, Beyaert R. T cell antigen receptor stimulation induces MALT1 paracaspase-mediated cleavage of the NF-kB inhibitor A20. Nat Immunol 2008; 9(3): 263-271

127. Goncharov T, Niessen K, de Almagro MC, Izrael-Tomasevic A, Fedorova AV, Varfolomeev E, Arnott D, Deshayes K, Kirkpatrick DS, Vucic D. OTUB1 modulates c-IAP1 stability to regulate 
signalling pathways. EMBO J 2013; 32(8): 1103-1114

128. Urbé S, Liu H, Hayes SD, Heride C, Rigden DJ, Clague MJ. Systematic survey of deubiquitinase localization identifies USP21 as a regulator of centrosome- and microtubule-associated functions. Mol Biol Cell 2012; 23(6): 1095-1103

129. Mueller T, Breuer P, Schmitt I, Walter J, Evert BO, Wüllner U. CK2-dependent phosphorylation determines cellular localization and stability of ataxin-3. Hum Mol Genet 2009; 18(17): 33343343

130. Scholz CC, Rodriguez J, Pickel C, Burr S, Fabrizio JA, Nolan KA, Spielmann P, Cavadas MA, Crifo B, Halligan DN, Nathan JA, Peet DJ, Wenger RH, Von Kriegsheim A, Cummins EP, Taylor CT. FIH regulates cellular metabolism through hydroxylation of the deubiquitinase OTUB1. PLoS Biol 2016; 14(1): e1002347

131. Soares L, Seroogy C, Skrenta H, Anandasabapathy N, Lovelace P, Chung CD, Engleman E, Fathman CG. Two isoforms of otubain 1 regulate T cell anergy via GRAIL. Nat Immunol 2004; 5(1): 45-54

132. Heideker J, Wertz IE. DUBs, the regulation of cell identity and disease. Biochem J 2015; 465(1): 1-26

133. Sun XX, Dai MS. Deubiquitinating enzyme regulation of the $\mathrm{p} 53$ pathway: a lesson from Otub1. World J Biol Chem 2014; 5(2): 7584

134. Luo J, Lu Z, Lu X, Chen L, Cao J, Zhang S, Ling Y, Zhou X. OTUD5 regulates $\mathrm{p} 53$ stability by deubiquitinating $\mathrm{p} 53$. PLoS One 2013; 8(10): e77682

135. Notarbartolo M, Poma P, Perri D, Dusonchet L, Cervello M, D'Alessandro N. Antitumor effects of curcumin, alone or in combination with cisplatin or doxorubicin, on human hepatic cancer cells. Analysis of their possible relationship to changes in $\mathrm{NF}-\kappa \mathrm{B}$ activation levels and in IAP gene expression. Cancer Lett 2005; 224(1): 53-65

136. Harhaj EW, Dixit VM. Regulation of NF- $\kappa B$ by deubiquitinases. Immunol Rev 2012; 246(1): 107-124

137. Harhaj EW, Dixit VM. Deubiquitinases in the regulation of NF- $\kappa B$ signaling. Cell Res 2011; 21(1): 22-39

138. Wei W, Li M, Wang J, Nie F, Li L. The E3 ubiquitin ligase ITCH negatively regulates canonical Wnt signaling by targeting dishevelled protein. Mol Cell Biol 2012; 32(19): 3903-3912

139. Takiuchi T, Nakagawa T, Tamiya H, Fujita H, Sasaki Y, Saeki Y, Takeda H, Sawasaki T, Buchberger A, Kimura T, Iwai K. Suppression of LUBAC-mediated linear ubiquitination by a specific interaction between LUBAC and the deubiquitinases CYLD and OTULIN. Genes Cells 2014; 19(3): 254-272

140. González-Navajas JM, Law J, Nguyen KP, Bhargava M, Corr MP, Varki N, Eckmann L, Hoffman HM, Lee J, Raz E. Interleukin 1 receptor signaling regulates DUBA expression and facilitates Tolllike receptor 9-driven antiinflammatory cytokine production. J Exp Med 2010; 207(13): 2799-2807

141. Enesa K, Zakkar M, Chaudhury H, Luong A, Rawlinson L, Mason JC, Haskard DO, Dean JL, Evans PC. NF-אB suppression by the deubiquitinating enzyme Cezanne: a novel negative feedback loop in pro-inflammatory signaling. J Biol Chem 2008; 283(11): 70367045

142. McNally RS, Davis BK, Clements CM, Accavitti-Loper MA, Mak TW, Ting JP. DJ-1 enhances cell survival through the binding of Cezanne, a negative regulator of NF-kB. J Biol Chem 2011; 286(6): 4098-4106
143. Zhu Y, Qu C, Hong X, Jia Y, Lin M, Luo Y, Lin F, Xie X, Xie X, Huang J, Wu Q, Qiu X, Piao D, Xing Y, Yu T, Lu Y, Huang Q, Yu C, Jin J, Zhang Z. Trabid inhibits hepatocellular carcinoma growth and metastasis by cleaving RNF8-induced K63 ubiquitination of Twist1. Cell Death Differ 2019; 26(2): 306-320

144. Choi J, Baek KH. Cellular functions of stem cell factors mediated by the ubiquitin-proteasome system. Cell Mol Life Sci 2018; 75(11): 1947-1957

145. Chandrasekaran AP, Suresh B, Kim HH, Kim KS, Ramakrishna S. Concise review: fate determination of stem cells by deubiquitinating enzymes. Stem Cells 2017; 35(1): 9-16

146. Ramakrishna S, Kim KS, Baek KH. Posttranslational modifications of defined embryonic reprogramming transcription factors. Cell Reprogram 2014; 16(2): 108-120

147. Naujokat C, Sarić T. Concise review: role and function of the ubiquitin-proteasome system in mammalian stem and progenitor cells. Stem Cells 2007; 25(10): 2408-2418

148. Schubbert S, Jiao J, Ruscetti M, Nakashima J, Wu S, Lei H, Xu Q, Yi W, Zhu H, Wu H. Methods for PTEN in stem cells and cancer stem cells. Methods Mol Biol 2016; 1388: 233-285

149. Duan S, Yuan G, Liu X, Ren R, Li J, Zhang W, Wu J, Xu X, Fu L, Li Y, Yang J, Zhang W, Bai R, Yi F, Suzuki K, Gao H, Esteban CR, Zhang C, Izpisua Belmonte JC, Chen Z, Wang X, Jiang T, Qu J, Tang F, Liu GH. PTEN deficiency reprogrammes human neural stem cells towards a glioblastoma stem cell-like phenotype. Nat Commun 2015; 6(1): 10068

150. Natarajan C, Takeda K. Regulation of various DNA repair pathways by E3 ubiquitin ligases. J Cancer Res Ther 2017; 13(2): 157-169

151. Schwertman P, Bekker-Jensen S, Mailand N. Regulation of DNA double-strand break repair by ubiquitin and ubiquitin-like modifiers. Nat Rev Mol Cell Biol 2016; 17(6): 379-394

152. Vlachostergios PJ, Patrikidou A, Daliani DD, Papandreou CN. The ubiquitin-proteasome system in cancer, a major player in DNA repair. Part 1: post-translational regulation. J Cell Mol Med 2009; 13(9b 9B): 3006-3018

153. Kee Y, Huang TT. Role of deubiquitinating enzymes in DNA repair. Mol Cell Biol 2016; 36(4): 524-544

154. Huen MS, Grant R, Manke I, Minn K, Yu X, Yaffe MB, Chen J. RNF8 transduces the DNA-damage signal via histone ubiquitylation and checkpoint protein assembly. Cell 2007; 131(5): 901-914

155. Kolas NK, Chapman JR, Nakada S, Ylanko J, Chahwan R, Sweeney FD, Panier S, Mendez M, Wildenhain J, Thomson TM, Pelletier L, Jackson SP, Durocher D. Orchestration of the DNAdamage response by the RNF8 ubiquitin ligase. Science 2007; 318(5856): 1637-1640

156. Mailand N, Bekker-Jensen S, Faustrup H, Melander F, Bartek J, Lukas C, Lukas J. RNF8 ubiquitylates histones at DNA doublestrand breaks and promotes assembly of repair proteins. Cell 2007; 131(5): 887-900

157. Jacomin AC, Taillebourg E, Fauvarque MO. Deubiquitinating enzymes related to autophagy: new therapeutic opportunities? Cells 2018; 7(8): E112

158. Magraoui FE, Reidick C, Meyer HE, Platta HW. Autophagyrelated deubiquitinating enzymes involved in health and disease. Cells 2015; 4(4): 596-621

159. Zinngrebe J, Montinaro A, Peltzer N, Walczak H. Ubiquitin in the 
immune system. EMBO Rep 2014; 15(1): 28-45

160. Bailey-Elkin BA, van Kasteren PB, Snijder EJ, Kikkert M, Mark BL. Viral OTU deubiquitinases: a structural and functional comparison. PLoS Pathog 2014; 10(3): e1003894

161. van Kasteren PB, Beugeling C, Ninaber DK, Frias-Staheli N, van Boheemen S, García-Sastre A, Snijder EJ, Kikkert M. Arterivirus and nairovirus ovarian tumor domain-containing deubiquitinases target activated RIG-I to control innate immune signaling. J Virol 2012; 86(2): 773-785

162. Frias-Staheli N, Giannakopoulos NV, Kikkert M, Taylor SL, Bridgen A, Paragas J, Richt JA, Rowland RR, Schmaljohn CS, Lenschow DJ, Snijder EJ, García-Sastre A, Virgin HW 4th. Ovarian tumor domain-containing viral proteases evade ubiquitinand ISG15-dependent innate immune responses. Cell Host Microbe 2007; 2(6): 404-416

163. Snijder EJ, Wassenaar AL, Spaan WJ, Gorbalenya AE. The arterivirus Nsp2 protease. An unusual cysteine protease with primary structure similarities to both papain-like and chymotrypsin-like proteases. J Biol Chem 1995; 270(28): 16671-16676

164. Bailey-Elkin BA, Knaap RCM, Kikkert M, Mark BL. Structure and function of viral deubiquitinating enzymes. J Mol Biol 2017; 429(22): 3441-3470

165. Feng W, Sun X, Shi N, Zhang M, Guan Z, Duan M. Influenza a virus NS1 protein induced A20 contributes to viral replication by suppressing interferon-induced antiviral response. Biochem Biophys Res Commun 2017; 482(4): 1107-1113

166. Yokota S, Okabayashi T, Yokosawa N, Fujii N. Measles virus P protein suppresses Toll-like receptor signal through up-regulation of ubiquitin-modifying enzyme A20. FASEB J 2008; 22(1): 74-83

167. Li S, Zheng H, Mao AP, Zhong B, Li Y, Liu Y, Gao Y, Ran Y, Tien $\mathrm{P}$, Shu HB. Regulation of virus-triggered signaling by
OTUB1- and OTUB2-mediated deubiquitination of TRAF3 and TRAF6. J Biol Chem 2010; 285(7): 4291-4297

168. Ning S, Pagano JS. The A20 deubiquitinase activity negatively regulates LMP1 activation of IRF7. J Virol 2010; 84(12): 61306138

169. Kumari P, Kumar H. Viral deubiquitinases: role in evasion of antiviral innate immunity. Crit Rev Microbiol 2018; 44(3): 304-317

170. Guo YC, Zhang SW, Yuan Q. Deubiquitinating enzymes and bone remodeling. Stem Cells Int 2018; 2018: 3712083

171. Mabilleau G, Chappard D, Sabokbar A. Role of the A20-TRAF6 axis in lipopolysaccharide-mediated osteoclastogenesis. J Biol Chem 2011; 286(5): 3242-3249

172. Lee MJ, Lim E, Mun S, Bae S, Murata K, Ivashkiv LB, Park-Min KH. Intravenous immunoglobulin (IVIG) attenuates TNF-induced pathologic bone resorption and suppresses osteoclastogenesis by inducing A20 expression. J Cell Physiol 2016; 231(2): 449-458

173. Kumari N, Jaynes PW, Saei A, Iyengar PV, Richard JLC, Eichhorn PJA. The roles of ubiquitin modifying enzymes in neoplastic disease. Biochim Biophys Acta Rev Cancer 2017; 1868(2): 456483

174. Ritorto MS, Ewan R, Perez-Oliva AB, Knebel A, Buhrlage SJ, Wightman M, Kelly SM, Wood NT, Virdee S, Gray NS, Morrice NA, Alessi DR, Trost M. Screening of DUB activity and specificity by MALDI-TOF mass spectrometry. Nat Commun 2014; 5(1): 4763

175. Harrigan JA, Jacq X, Martin NM, Jackson SP. Deubiquitylating enzymes and drug discovery: emerging opportunities. Nat Rev Drug Discov 2018; 17(1): 57-78

176. Ji S, Luo Y, Cai Q, Cao Z, Zhao Y, Mei J, Li C, Xia P, Xie Z, Xia Z, Zhang J, Sun Q, Chen D. LC domain-mediated coalescence is essential for Otu enzymatic activity to extend Drosophila lifespan. Mol Cell 2019; 74(2): 363-377.e5 